University of Nebraska - Lincoln

DigitalCommons@University of Nebraska - Lincoln

Drought Mitigation Center Faculty Publications Drought -- National Drought Mitigation Center

$3-2020$

\title{
Utilizing Objective Drought Severity Thresholds to Improve Drought Monitoring
}

Zachary T. Leasor

Ohio State University, leasor.4@osu.edu

Steven M. Quiring

Ohio State University, quiring.10@osu.edu

Mark D. Svoboda

University of Nebraska-Lincoln, msvoboda2@unl.edu

Follow this and additional works at: https://digitalcommons.unl.edu/droughtfacpub

Part of the Climate Commons, Environmental Indicators and Impact Assessment Commons, Environmental Monitoring Commons, Hydrology Commons, Other Earth Sciences Commons, and the Water Resource Management Commons

Leasor, Zachary T.; Quiring, Steven M.; and Svoboda, Mark D., "Utilizing Objective Drought Severity Thresholds to Improve Drought Monitoring" (2020). Drought Mitigation Center Faculty Publications. 171. https://digitalcommons.unl.edu/droughtfacpub/171

This Article is brought to you for free and open access by the Drought -- National Drought Mitigation Center at DigitalCommons@University of Nebraska - Lincoln. It has been accepted for inclusion in Drought Mitigation Center Faculty Publications by an authorized administrator of DigitalCommons@University of Nebraska - Lincoln. 


\title{
Utilizing Objective Drought Severity Thresholds to Improve Drought Monitoring
}

\author{
ZACHARY T. LEASOR AND STEVEN M. QUIRING \\ Atmospheric Sciences Program, Department of Geography, The Ohio State University, Columbus, Ohio \\ MARK D. SVOBODA \\ National Drought Mitigation Center, School of Natural Resources, University of Nebraska-Lincoln, Lincoln, Nebraska
}

(Manuscript received 4 September 2019, in final form 13 January 2020)

\begin{abstract}
Drought is a prominent climatic hazard in the south-central United States. Drought severity is frequently classified using the categories established by the U.S. Drought Monitor (USDM). This study evaluates whether the thresholds for the standardized precipitation index (SPI) used by the USDM accurately classify drought severity. This study uses the SPI based on PRISM precipitation data from 1900 to 2015 to evaluate drought severity in Texas, Oklahoma, and Kansas. The results show that the fixed SPI thresholds for the USDM drought categories may lead to a systematic underestimation of drought severity in arid regions. To address this issue, objective drought thresholds were developed at each location by fitting a cumulative distribution function at each location to ensure that the observed frequency of drought in each severity category (D0-D4) matched the theoretical expectations of the USDM. This approach reduces the systematic biases in drought severity across the western portion of the study region. Therefore, we recommend developing objective drought thresholds for each location and SPI time scale (e.g., 1, 3, and 6 months). This method can be used to develop objective drought thresholds for any drought index and climate region of interest.
\end{abstract}

\section{Introduction}

Drought is characterized by precipitation deficits that have an effect on both the environment and its ecosystems (Heim 2002). Drought is one of the most complex natural hazards because it is difficult to quantify drought severity (Wilhite and Pulwarty 2017) and assess drought impacts given the large number of systems affected (Wilhite 2000). The task of monitoring drought conditions and defining drought severity is further complicated because the characteristics of drought vary with space and environmental circumstances. Therefore, a versatile and objective framework for monitoring the occurrence and severity of drought is necessary. This framework requires specific operational drought definitions such as those used by the U.S. Drought Monitor (USDM) to quantify the beginning, end, and severity of drought events (Quiring 2009a).

The USDM is jointly produced by the National Drought Mitigation Center at the University of Nebraska-Lincoln, the U.S. Department of Agriculture, and the National Oceanic and Atmospheric Administration. The USDM

\footnotetext{
Corresponding author: Zachary Leasor, leasor.4@osu.edu
}

uses a convergence-of-evidence approach, which is subjective, to classify and map drought based on numerous inputs (Svoboda et al. 2002; Svoboda 2016). The weekly USDM map is based on measurements of meteorological, hydrological, and soil conditions as well as reported impacts and observations from more than 400 contributors around the country. It is used by policymakers and media in discussions of drought and in allocations of drought relief. The U.S. Department of Agriculture's Farm Service Agency uses the USDM to distribute relief through various disaster assistance programs. The Internal Revenue Service uses the USDM to determine the replacement period for livestock sold because of drought. In addition, the U.S. Department of Agriculture uses the USDM to make disaster declarations for any county that has been in severe drought for at least eight consecutive weeks. Therefore, the method used by the USDM to determine drought severity has a direct financial impact on farmers and ranchers in the United States and any biases or limitations in the method for establishing drought severity have substantial impacts in terms of drought mitigation and response.

Typically, operational drought definitions are established using drought indices. The USDM employs fixed 
drought thresholds that can be applied to a wide array of drought indicators and indices to evaluate drought severity (Svoboda et al. 2002). These thresholds are referred to as fixed because they do not vary over space or time. When using the fixed thresholds with a wide array of index data, there can be instances where the expected recurrence intervals associated with each threshold are not met. The USDM is aware of this potential issue and authors frequently use their expert judgment to consider the changing characteristics of drought indices and weight each source of data accordingly. This is why a convergence-of-evidence approach is used, so that drought declarations are informed by many different sources of drought information. The strength of this approach is that the USDM authors are experts in the drought monitoring field who are highly qualified to analyze many different sources of drought index and indicator data. However, the process for evaluating each index is subjective and informal. Therefore, an objective method that adjusts severity thresholds to better match historical representations of drought can improve drought classification accuracy. The purpose of this study is to develop objective operational drought thresholds following the method outlined by Quiring (2009b) and to evaluate how these thresholds influence the classification of drought severity. The purpose of defining objective operational drought thresholds is to ensure that drought characteristics can be compared across different climate regions by using severity thresholds that are customized for each climate region.

Past studies have developed two methods for determining objective drought thresholds. Goodrich and Ellis (2006) used the empirical distribution of the SPI to develop objective drought thresholds in Arizona. They found that, in some cases, the objective drought thresholds differed substantially from the fixed thresholds (e.g., -2.7 vs -2.0 for D4). However, they found that there was not a consistent pattern among stations. At some locations, the objective drought thresholds were more extreme than the fixed thresholds, while at others they were less extreme. Building upon these findings, Quiring (2009b) developed objective drought thresholds at each location by fitting a probability density function (PDF) to the drought index data. When these thresholds were applied to Texas, where mean annual precipitation varies significantly across the state, the normal distribution fit the index well at most locations in Texas. Both of these studies show that objective drought thresholds can help to address issues associated with spatial variance in drought indices (Goodrich and Ellis 2006; Quiring 2009b).

To align with previous research, this study will calculate objective drought thresholds using the standardized precipitation index (SPI). Even though the SPI is frequently used to compare precipitation conditions among different regions, the SPI is not spatially invariant (Quiring 2009b). This means that locations with differences in mean and intra-annual precipitation result in varying SPI distributions. For example, Quiring (2009b) demonstrated that drier locations had less extreme drought thresholds than wetter locations. The variance of the SPI is generally acknowledged and taken into account when used as a drought monitoring tool. For example, in arid regions or seasons the 1-month SPI may be ignored or supplemented with longer SPI time scales to account for biases that occur when there are months with no precipitation. However, it can be difficult to determine how the SPI should be used based only on prior knowledge or expert judgement. Therefore, an objective analysis detailing the performance of the SPI can help to formally identify spatially and seasonally variant strengths and weaknesses of the index. This analysis can be a complementary tool used to weight the influence of the SPI in a blending evaluation such as the convergence-of-evidence approach.

This study will develop objective drought thresholds for a multistate region in the south-central United States to assess the impact that objective drought thresholds have on drought frequency. It is important to emphasize that the USDM maps are drawn using a convergenceof-evidence approach. They rely not only on objective measures of drought (drought indices and thresholds), but also consider drought impacts and input from local experts. Therefore, through this process, the USDM is able to integrate a rich and diverse set of information so that drought severity can be accurately assessed in each region. This paper demonstrates a method for providing better information to inform drought monitoring activities, including the USDM. This information is not meant to replace expert input/judgement, but to complement and support it by providing severity thresholds that have been objectively defined based on the climatic conditions at each location. The potential impact of adopting objective drought thresholds is shown by examining differences in the drought-affected area for a recent drought event.

\section{Data and methods}

\section{a. Study area}

The study region includes Kansas, Oklahoma, and Texas. These states were chosen because there is significant intraregional climate variability due to a notable east-west precipitation gradient (Basara et al. 2013). The south-central United States is also characterized by high rates of evapotranspiration during the warm season 
that can exacerbate drought conditions through rapid drying of the land surface. In response to these climatic characteristics, previous research has shown the tendency for drought in this region to be less frequent and lengthier than droughts in other regions of the United States (Mo and Schemm 2008; Soulé 1992). The primary forcing for drought in the south-central United States is persistent La Niña conditions, particularly during the cool season (Mo et al. 2009; Pu et al. 2016). While the linkage between ENSO and climate variability is weaker during the warm season, the coupling impacts are not always instantaneous. Antecedent sea surface temperatures (SSTs) may be more important for drought onset, which typically requires an accumulation of precipitation deficits over several months (Mo 2011). Otherwise, drought in the warm season can be influenced the modulation of ENSO by other teleconnections, largescale circulation patterns, fluctuations in the Great Plains low-level jet (LLJ), and land-atmosphere feedbacks (Basara et al. 2013; Pu et al. 2016; Ryu and Hayhoe 2017).

The south-central United States is most sensitive to precipitation deficits during summer months when evapotranspiration rates are highest. Flash drought is therefore a critical hazard because short-term precipitation deficits can lead to rapid drought onset and intensification occurring in a matter of weeks (Christian et al. 2019; Otkin et al. 2018). Rapid drought recovery can also take place in the south-central United States when heavy precipitation from tropical cyclone activity, a strengthening of the LLJ, or mesoscale convective systems (MCS) impact areas where drought is occurring (Kam et al. 2013; Hodges and Pu 2019; Song et al. 2019). The large number of processes impacting drought in this region occur across widely varying time scales. Thus, the south-central United States is an ideal location to examine the behavior of the SPI because a strength of this index is the ability to characterize drought across different time scales and climate types. Despite a great deal of uncertainty surrounding future projections of drought, increasing temperatures will result in a higher sensitivity to precipitation deficits, consequently raising the chance for droughts to worsen in severity and length (Basara et al. 2013; Ryu and Hayhoe 2017). Therefore, objective and accurate classification of drought severity is essential because changes in drought characteristics can have a large impact on crops, livestock production, water supply, and forestry in the south-central United States (Steiner et al. 2018).

\section{b. Precipitation data}

This study utilizes monthly precipitation data from the Parameter-Elevation Regressions on Independent Slopes Model (PRISM; http://www.prism.oregonstate.edu).
Monthly precipitation data are derived using the PRISM linear regression model designed to spatially interpolate precipitation onto a national grid. PRISM estimates precipitation using a digital elevation model (DEM) as the explanatory variable with nearby stations weighted by distance, elevation, clustering, topography estimated using a two-layer atmosphere, coastal proximity, and terrain weights (Daly et al. 2000,1994). One strength of PRISM is that it develops a regression model for each grid cell, allowing for flexibility in different regions (Daly et al. 2000). Precipitation data are interpolated from a number of different station networks (Daly et al. 2000). Station data from 32 regional and national networks are included in the interpolation (http://www.prism.oregonstate.edu/ documents/PRISM_datasets.pdf). In this study, the PRISM "ppt AN81m" data are used to produce the highest spatial resolution of precipitation for each month. The ppt AN81m dataset uses climatologically aided interpolation based on the 1981-2010 precipitation climatology to improve the accuracy of the data. It also uses radar-estimated precipitation from 2002 to the present. The PRISM datasets have been shown to be more accurate than both the WorldClim and Daymet grids (Daly et al. 2008). Using a jackknife cross validation, Daly et al. (2008) found that the mean absolute errors (MAE) between precipitation observations and monthly PRISM data are lowest in the central United States, with MAE ranging from 3.30 to $6.14 \mathrm{~mm}$. The largest errors were found where station density is lowest in western Texas, and some stations reported errors greater than $20 \%$ (Daly et al. 2008). Monthly PRISM precipitation data at $2.5 \operatorname{arc} \min (\sim 4 \mathrm{~km})$ resolution from 1900 to 2015 were used, resulting in a period of record of 1392 months. The precipitation data were clipped to the states of Texas, Oklahoma, and Kansas, which results in a total of 60634 grid cells.

\section{c. Standardized precipitation index}

Prior to the 1990s, the Palmer drought severity index was the most widely used index for drought monitoring. There has been a shift over time, and the SPI has become more widely used for drought monitoring. The SPI is a popular drought index because of its elegance and simplicity, given that it only requires precipitation data (McKee et al. 1993). Previous evaluations of drought indices, such as Quiring (2009a), have shown that the SPI qualitatively outperforms other drought indices. In addition, Hayes et al. (2011) encouraged a global adoption of the SPI as the primary index for drought monitoring. Another advantage of the SPI is that it can be calculated at different time scales, so it can be used to monitor meteorological, agricultural, and hydrological drought. Typically, SPI time scales of $<6$ months are 
used to monitor short-term droughts, whereas time scales of $\geq 6$ months are used to monitor droughts with long-term impacts. During flash drought, a phenomenon characterized by the rapid onset and deterioration of drought conditions (Otkin et al. 2018), short SPI time scales (1-3 months) may be used to detect trends in precipitation that help to monitor rapidly changing drought conditions. Another popular index, the standardized precipitation evapotranspiration index, leverages the flexible calculation of the SPI and combines precipitation with potential evapotranspiration data to better match drought conditions (Vicente-Serrano et al. 2012). However, this study will only use the SPI so that results can be analyzed using differences in precipitation characteristics.

The SPI is calculated using a PDF that normalizes the precipitation data. In this case, a two-parameter gamma cumulative distribution function (CDF) is used to fit precipitation data, where the parameters are estimated by the maximum likelihood method. The shape parameter $\alpha$ and scale parameter $\beta$ used by the gamma distribution find the cumulative probability associated with each monthly precipitation event. The gamma variate is transformed to a normal distribution using an equiprobability transformation so that a given value in the gamma CDF has the same probability in a normal distribution. Previous research has investigated the role that the selected function used to fit precipitation data has upon the distribution of SPI values, particularly in arid regions (Quiring 2009b; Wu et al. 2007). Although the two-parameter gamma function may not provide the best fit for every location, this method of calculating the SPI is suggested by McKee et al. (1993) and is used in the National Drought Mitigation Center (NDMC) SPI program (https://drought.unl.edu/droughtmonitoring/SPI/ SPIProgram.aspx). Guttman (1999) suggested that the Pearson type-III distribution may perform better when fitting precipitation data, particularly for extreme values in the lower tail. However, for consistency, this study will employ the two-parameter gamma function to fit precipitation data at all locations within the study region. The MATLAB software code used to calculate the SPI was developed in December of 2009 by T. Lee of L'Institut National de la Recherche Scientifique-Eau Terre Environnement (INRS-ETE) in Quebec, Canada. This code uses the same method as NDMC to generate the SPI.

This study uses a simplified approach for establishing objective drought thresholds so that it is feasible to apply in an operational setting. This also facilitated a clear and concise presentation of the results. For example, we chose to use the two-parameter gamma PDF to calculate the SPI even though previous research found that other
PDFs (Pearson type III) may work better in arid regions (Quiring 2009b; Wu et al. 2007). We used the method recommended by the NDMC rather than calculating the SPI using a different method in more arid and humid regions. This is a more practical approach from an operational drought monitoring standpoint, since it would be complicated to calculate the SPI in different ways in each climate region within the United States. The SPI is commonly calculated using the two-parameter gamma PDF, so the results that are presented here are consistent with current drought monitoring practices in the United States. However, we acknowledge that one way to improve the effectiveness of fixed drought thresholds is to determine the most appropriate method for calculating the SPI at each location. This would improve the spatial comparability (invariance) of the SPI.

Our study examines the SPI at 1-, 3-, 6-, and 12-month time scales. The 1-month SPI is calculated from 1900 to 2015, and the 3-, 6-, and 12-month SPI are calculated using data from 1901 to 2015. These four SPI time scales were selected to represent a range of time scales that are of interest for monitoring meteorological, agricultural, and hydrological drought. The 1-month SPI is useful for examining monthly precipitation, and it provides an early indicator for transitions between wet and dry periods. During the warm season, the 1-month SPI may represent near-surface soil moisture and it can be used by agricultural producers to monitor crop stress ( $\mathrm{Ji}$ and Peters 2003). The 3- and 6-month SPI represent longerterm precipitation conditions. These time scales characterize interseasonal variations in precipitation, and agricultural producers may use the 3- and 6-month SPI to represent the moisture status during the growing season. The 12-month SPI reflects longer-term precipitation conditions that are related to lake and reservoir levels (Vicente-Serrano and López-Moreno 2005). Despite the popularity of the SPI, it is important to keep in mind that it is a statistical transformation of precipitation and therefore it does not reflect all the relevant physical processes that influence drought, such as evaporative demand and runoff.

\section{d. Objective drought thresholds}

This study presents a method for determining objective drought thresholds. Objective drought thresholds are developed for each location using the best-fitting CDF. While there are many distributions that may characterize a distribution of SPI values, the primary assumption is that a long time series of SPI values follows a normal distribution. However, as a result of the aforementioned issues with fitting precipitation data in arid regions, SPI distributions may vary in both kurtosis and skewness. For example, a SPI distribution derived 


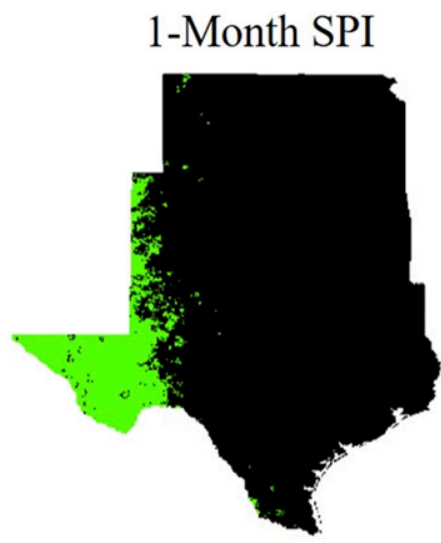

6-Month SPI

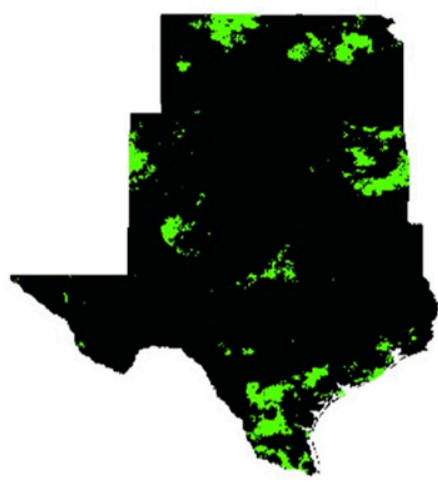

3-Month SPI

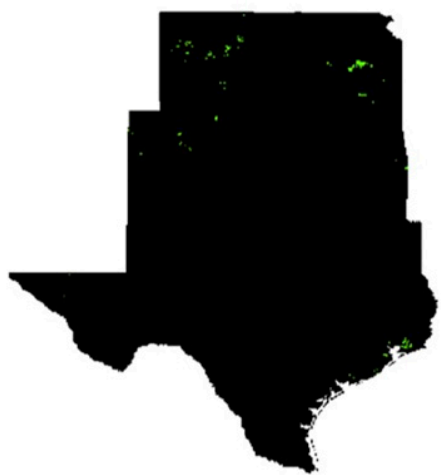

12-Month SPI

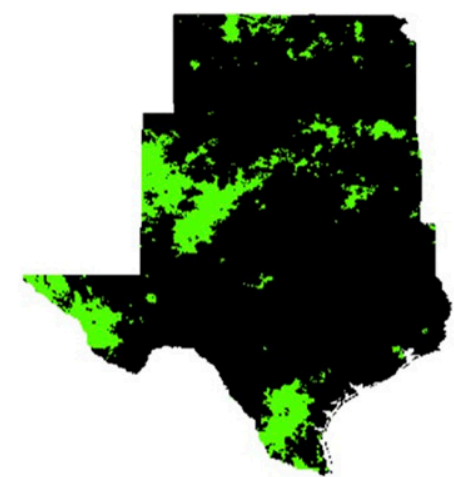

Best Fitting Distribution

According to Minimum

KS-Statistic

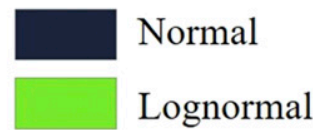

FIG. 1. Study region maps showing which distribution provides the best fit (i.e., minimizes the KS statistic) for the standardized precipitation index in each grid cell. The 1-month SPI was calculated on the basis of monthly data from 1900 to 2015, and the 3-, 6-, and 12-month SPI time scales were calculated on the basis of monthly data from 1901 to 2015.

from precipitation data that contain many zeros, such as is common in more arid regions, may be positively skewed. Fitting a distribution to SPI data is an intermediate step in determining severity thresholds and it is important to use a distribution that minimizes error in fitting precipitation data. Therefore, this study fits the SPI data with both a normal or lognormal distribution and then tests which one provides the best fit using the Kolmogorov-Smirnov (KS) Lilliefors test. The KS Lilliefors test was chosen for analysis because the parameters for each distribution are unknown and must be estimated (Razali and Wah 2011). While other distributions could be considered, for simplicity, the lognormal distribution is used to represent any distribution that is positively skewed. The minimized KS statistic is used to determine whether the normal or lognormal distribution best fits the SPI distribution for each location (Fig. 1).

Using the 1-month SPI, results (Fig. 1) show that the lognormal distribution is generally most appropriate in the western portion of the study region where the climate is mostly classified as semiarid or arid (Peel et al. 2007). The normal distribution is most appropriate in the rest of the study area. There are also locations where the lognormal distribution is most appropriate when using longer SPI time scales, although the lack of a clear spatial pattern suggests that these locations are not influenced by aridity. Instead, distributions of SPI at longer time scales may be attributed to natural variability (random variation) in the climate record because there are no distinct spatial patterns associated with the best distribution fit. Thus, when historical conditions are used to derive a distribution of SPI data in a data-driven approach, the probability of drought reaching a fixed threshold can vary because of nonstationarity in the historical data. After the best-fitting CDF for the SPI was determined, objective drought thresholds were created using the drought severity categories that are described in Svoboda et al. (2002) and employed by the USDM (Table 1). The SPI percentiles associated with each severity category are used to determine the new objective threshold. For example, the 
TABLE 1. Drought frequency (1900-2015) for the 1-month SPI. Drought thresholds are based on the USDM categories as reported by Svoboda et al. (2002). The SPI values listed in the second column are the fixed thresholds that are used to classify drought severity (D0-D4). The fifth column reports the number of months between 1900 and 2015 for which the 1-month SPI should fall within the range. The third column reports frequency as a percentage [number of months/total number of months $(N=1392)$ ]. Results are based on using a normal distribution of SPI values with a mean of 0 and standard deviation of 1 .

\begin{tabular}{ccccc}
\hline \hline $\begin{array}{c}\text { Drought } \\
\text { threshold }\end{array}$ & SPI & Percentage of months (\%) & Cumulative percentiles (\%) & $\begin{array}{c}\text { No. of months } \\
\text { (rounded to nearest integer) }\end{array}$ \\
\hline All & SPI $\leq-0.5$ & 30.9 & 69.1 & 429 \\
D0 & $-0.8<$ SPI $\leq-0.5$ & 9.7 & 69.1 & 134 \\
D1 & $-1.3<$ SPI $\leq-0.8$ & 11.5 & 78.8 & 160 \\
D2 & $-1.6<$ SPI $\leq-1.3$ & 4.2 & 90.3 & 58 \\
D3 & $-2.0<$ SPI $\leq-1.6$ & 3.2 & 94.5 & 45 \\
D4 & SPI $\leq-2.0$ & 2.3 & 97.7 & 32 \\
\hline
\end{tabular}

percentile associated with the SPI value of a D4 drought $(-2.0)$ is 2.3 because the SPI represents a $z$ score that encompasses all but $2.3 \%$ of the data in the left tail of the distribution. Therefore, at each grid cell in the study region the best-fitting CDF is used to determine the SPI value associated with a percentile of 2.3. This provides an objectively defined D4 threshold at each location in the study region. Using this method, objective thresholds are related only to the historical data and the CDF used to fit and standardize the drought index. This process is repeated for each drought severity category: D0, D1, D2, D3, and D4.

\section{Results}

\section{a. Drought frequency as a function of severity}

The frequency of occurrence for each drought severity category is determined using the fixed (i.e., same SPI threshold at every location) severity thresholds designated by the USDM. The frequency of occurrence is the number of months within each drought category. Due to the formulation of the SPI, it is possible to estimate the expected occurrences of each severity threshold. Table 1 describes the probabilities and frequencies of SPI values for each drought category based on the fixed thresholds used by the USDM. One important note is that D0 indicates abnormally dry conditions, not drought. However, for convenience, the frequency of D0 events will be calculated and evaluated along with the other four drought severity categories.

If the SPI were spatially invariant, the observed drought frequencies should align closely with those reported Table 1 . The period of record for each grid cell provides a large enough sample size that the SPI distribution should approach normality. Figure 2 shows the proportional difference between the observed and theoretical severity frequencies. For example, a proportional difference of 2 indicates that the number of times that a drought of a given severity occurred was double the expected frequency shown in Table 1. When using the 1-month SPI, the spatial pattern of the proportional differences for D0 are relatively homogeneous, except in western portions of the study area where some locations exhibit higher frequencies. For example, near El Paso, Texas, D0 conditions occur in 157 months whereas D0 frequencies are lower in Topeka, Kansas (123 months), and Oklahoma City, Oklahoma (108 months). The area with the most D1 conditions is also the western Texas Panhandle with a homogeneous pattern of lower drought frequencies across the rest of the study area. The highest frequency of D2 and D3 conditions is located in a northsouth band that stretches from central Texas to western Kansas. As compared to D0 and D1 conditions, the location of highest drought frequency is farther east. In west Texas, there is a concentrated region of lower D2 and D3 frequencies that is likely a result of the high frequencies of lower-severity conditions.

For D4 conditions, there is a distinct east-west frequency gradient across the study region. The D4 conditions occur in 45 months in Tyler, Texas; 32 months in Oklahoma City; and 5 months in El Paso. The minimum frequency for D4 droughts is zero. This illustrates a potential issue with using fixed USDM thresholds with the 1-month SPI. As shown in Table 1, the expected number of months of D4 conditions is 32 months. Therefore, it is obvious that using fixed drought thresholds with the 1-month SPI can lead to systematically overestimating the occurrence of D4 conditions in wetter locations (Tyler) and systematically underestimating the occurrence of D4 conditions in drier locations (El Paso). Even though the 1-month SPI should be standardized, results show the SPI to be spatially variant and unable to standardize precipitation at some locations in the study region because drought is represented differently across varying climates. This potential bias is also evident using other precipitation datasets.

The drought frequency results using the 1-month SPI show that there is a higher than expected frequency of 

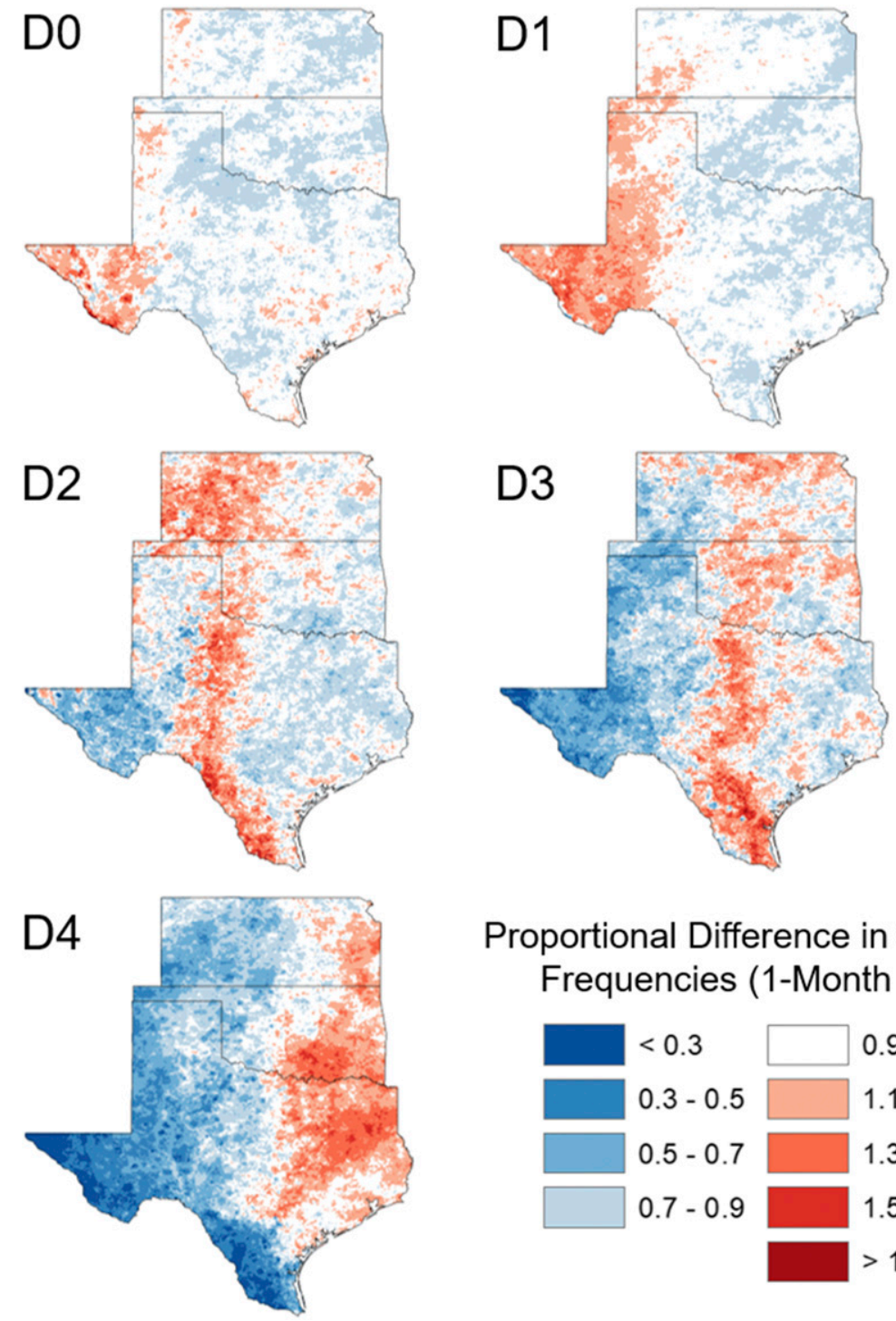

\section{Proportional Difference in Severity Frequencies (1-Month SPI)}

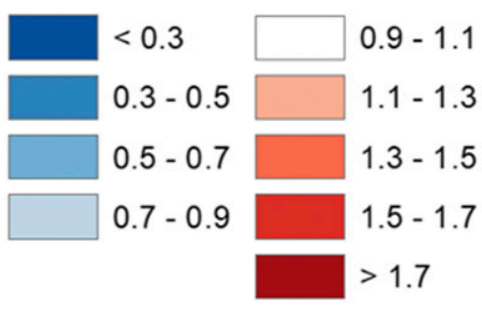

FIG. 2. Proportional difference in frequency associated with each USDM severity category (Table 1) between 1900 and 2015 based on the 1-month SPI. The proportional difference represents the number of months in which a given severity occurred divided by the theoretical (or expected) frequency shown in Table 1. Areas in blue indicate that the number of droughts of a given severity (D0-D4) occur less frequently than expected. Areas in red indicate that droughts of a given severity (D0-D4) occur more frequently than expected. If the observed frequency matches the theoretical frequency established by USDM, then most values should be near 1 (white).

D0 and D1 conditions in the western portion of the region and a lower than expected frequency of D3 and D4 conditions. At longer SPI time scales (see Figs. A1-A3 in appendix A), the severity frequencies for D0, D1, and D2 conditions are relatively homogeneous and there are areas with disproportionate frequencies for D3 and D4 conditions. In contrast to the 1-month SPI, the residual spatial patterns appear to be associated with factors other than aridity, such as natural variability in the climate record or local extreme events, which may skew the distributions of SPI values. For example, there is a general overestimation of D4 severities across most of Texas using the 3-month SPI, and even though the overestimation of $\mathrm{D} 4$ severities using the 6- and 12-month SPI is not as widespread, the spatial patterns do not coincide with any climatological patterns. Even when using proportional differences to standardize frequencies across severity categories, the smaller sample 

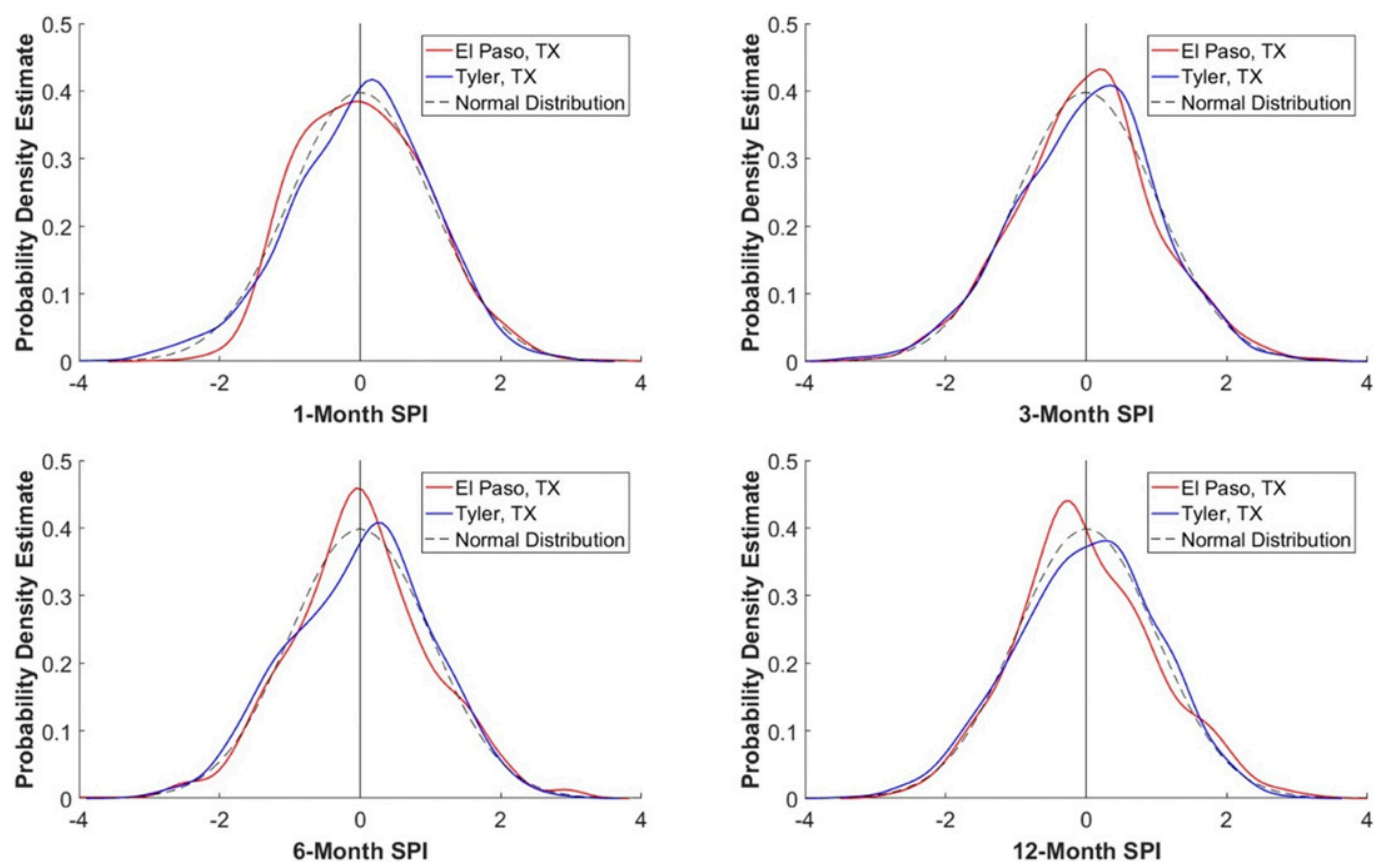

FIG. 3. PDF for the SPI values in El Paso (red) and Tyler (blue). The 1-month SPI is based on 1900-2015 ( $n=1392$ months), and the 3-, 6-, and 12-month SPI time scales are based on 1901-2015 ( $n=1380$ months). The distributions were created by using a normal kernel-smoothing function with a bandwidth of 1 . The density is evaluated at 100 equally spaced points covering the range of the SPI. For reference, the black dashed line is the PDF of a normal distribution.

size of D3 and D4 conditions exacerbates the heterogeneities. However, there is clear evidence (see Figs. A1-A3 in appendix A) that the heterogeneity of severity frequencies increases with increasing SPI time scales. Disproportionate severity frequencies are expected in the western regions when using the 1-month SPI during typically dry months. The heterogeneity of severity frequencies at 3-, 6-, and 12-month time scales suggests that the inability of the SPI to standardize precipitation at some locations is not limited to the 1-month SPI.

If the SPI were spatially invariant, these large differences in drought frequency would not be observed. The results suggest that when precipitation data from different climate regimes are fit with a PDF to calculate the SPI, the kurtosis, or shape characteristic, of the SPI distribution may differ. Using the 1-month SPI, drier locations may have a leptokurtic distribution, characterized by a small variance in SPI values with respect to the mean. Wetter locations may tend to have a larger variance in SPI values, resulting in a platykurtic distribution. To test this hypothesis, the distribution of SPI values from two climatically distinct locations will be compared, a relatively dry location near El Paso and a relatively wet location near Tyler.

According to Fig. 3, the properties of the 1-month SPI distribution vary between the two locations. Specifically, the left tail of the El Paso distribution has less variance (0.83) relative to the mean than the Tyler distribution (1.00). Thus, the El Paso distribution has less kurtosis (2.81) than the Tyler distribution (3.39). The means of the El Paso distribution (0.06) and Tyler distribution (0.00) also differ. The El Paso distribution also has a positive skew (0.30) that becomes apparent when SPI $<0.5$. The greatest disparity between empirical distributions for El Paso and Tyler is when the SPI is approximately \pm 0.5 . This result implies that there are many more months that have an SPI of 0.5 in Tyler and -0.5 in El Paso. Although the SPI is designed to create a normal distribution that is identical at all locations, this example demonstrates that this does not always happen. At longer SPI time scales, SPI distributions still have the tendency to exhibit differences in skew and kurtosis. For example, using the 6- and 12-month SPI, the distributions for Tyler suggest that SPI values ranging from approximately -1 to 0 are clearly underrepresented. While it is more difficult to speculate on the reasons for this variability, the results suggest that distributions of SPI differ at all time scales (Fig. 2).

\section{b. Objective drought thresholds}

After the best-fitting PDF was determined for each location, objective drought thresholds were created. 


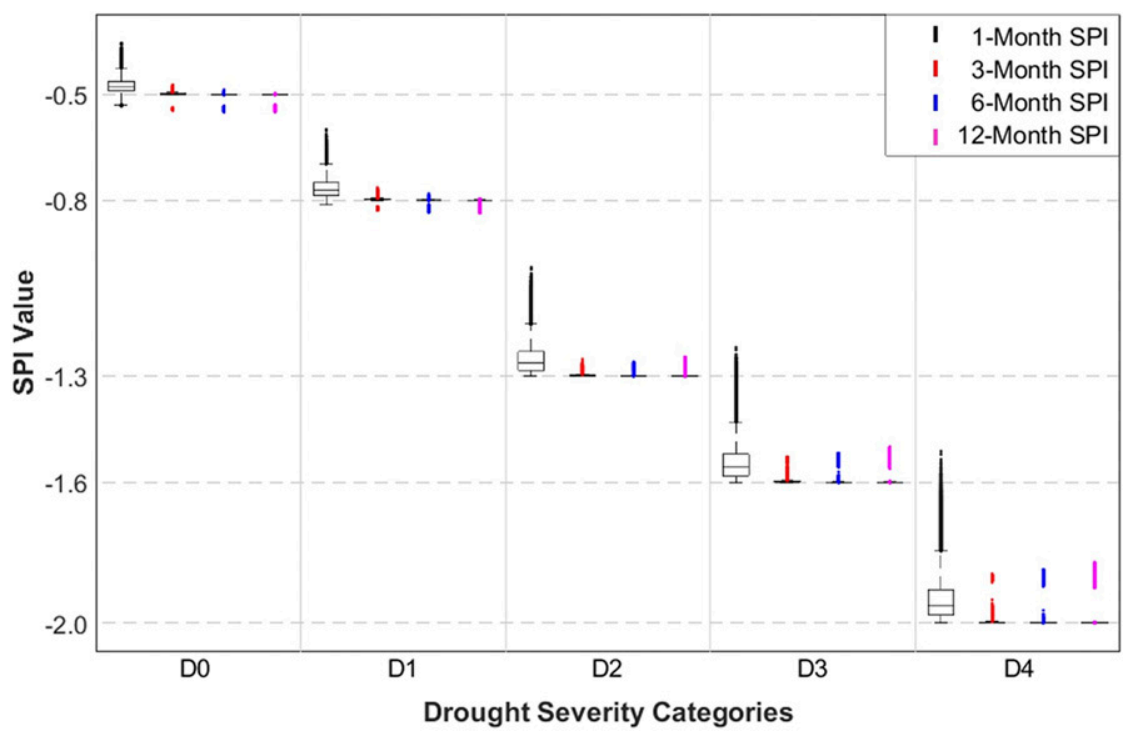

FIG. 4. Comparison of the distributions of the objective drought thresholds for each of the USDM severity categories (D0-D4) for the 1-3-, 6-, and 12-month SPI across the study area. SPI time scales are denoted by the color of outliers. The dashed horizontal lines indicate the fixed USDM drought thresholds $(\mathrm{D} 4=-2.0 ; \mathrm{D} 3=-1.6 ; \mathrm{D} 2=-1.3 ; \mathrm{D} 1=-0.8 ; \mathrm{D} 0=-0.5)$. The top of each box represents the 75th percentile of the distribution, and the bottom represents the 25 th percentile. The solid horizontal line in the box displays the median of the distribution. Whiskers extend to \pm 2.7 standard deviations from the mean, and all other values are considered to be outliers and are plotted as dots.

Figure 4 displays the variation in drought severity thresholds across the study region using the objective method. Each boxplot represents a distribution for the range in objective drought threshold values for all grid cells in the study area. The severity threshold at each location is based on a singular value. The objective drought thresholds for the 1-month SPI are generally less extreme (i.e., closer to 0) than the fixed drought thresholds for all drought severity categories (D0-D4). This is not the case for the 3-, 6-, and 12-month SPI. At longer time scales, the boxplots are tightly centered on the fixed drought threshold for all drought severity categories (D0-D4). There are thousands of outlying thresholds for each severity and SPI time scales. These outliers represent locations where the lognormal distribution provides the best fit. As the severity increases, the range of objective thresholds also increases for all SPI time scales, but it is most pronounced for the 1-month SPI. This is not surprising given that the objective drought thresholds will be most variable in the tails of the distribution, as shown by Quiring (2009b). In this study, we are only concerned with the left tail (driest conditions). According to Fig. 4, there are locations in which the fixed drought classification may underrepresent drought severity by one category when considering the most extreme conditions (D3 and D4). While this issue is most pronounced for the 1-month SPI, Fig. 4 shows that longer SPI time scales also have locations where the drought severity is underestimated based on fixed thresholds. This suggests that using fixed SPI thresholds is not the best approach for determining drought severity.

In addition to examining spatial variations in objective drought thresholds, we also explore whether there are seasonal variations. Previous studies did not consider whether it was necessary to develop separate drought thresholds for each month (Goodrich and Ellis 2006; Quiring 2009b). In part, this is because the focus of these previous studies was on drought at longer time scales. Here we consider the role that seasonality may have on determining objective drought thresholds. Figure 5 shows the seasonal variation in drought frequency for each drought severity (D0-D4) for all SPI time scales. The seasonal variability in frequencies is only clearly apparent with the 1-month SPI. This is likely attributed to the inability of the 1-month SPI to standardize precipitation during dry months in locations with large intra-annual variability of precipitation. Seasonal precipitation patterns that result in more months with no precipitation impact the calculation of the SPI similar to arid regions. At longer SPI time scales, seasonal variations are less pronounced and monthly thresholds therefore do not display significant interseasonal variability.

Using the 1-month SPI, it is evident that, even after applying objective drought thresholds, there is still 

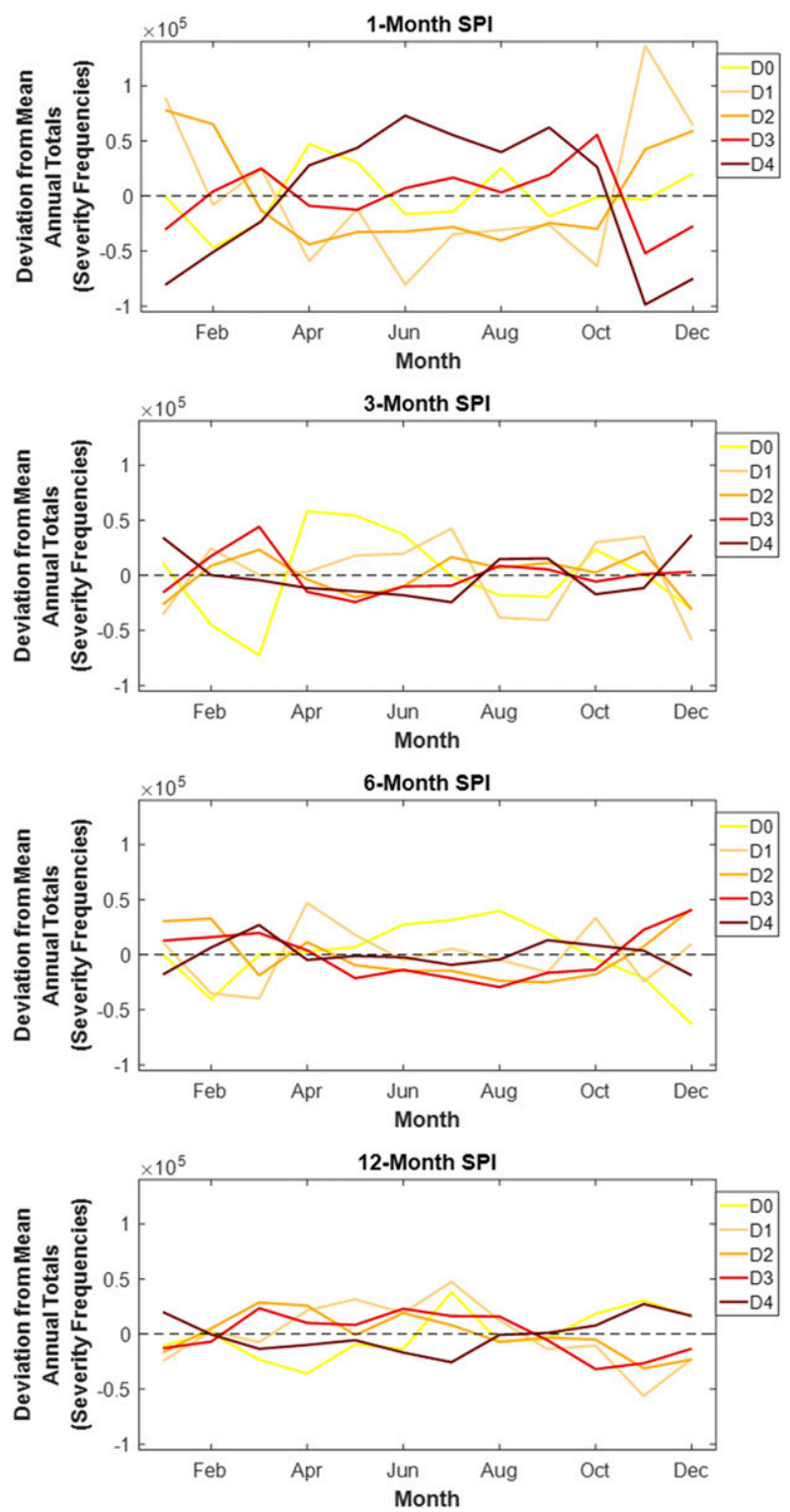

FIG. 5. Seasonal distributions of drought frequencies for each drought severity (D0-D4) using objective drought thresholds with the SPI. Frequencies were determined for each month by summing of the number of grid cells experiencing a drought for each severity category from 1900 to 2015 using the 1-month SPI and 1901-2015 using the 3-, 6-, and 12-month SPI. An annual mean was then calculated for each severity category, and the frequencies were then expressed as the deviation from the mean annual frequency.

seasonal variability in the relative frequencies of drought severity categories. During the warm season (March-October) there are more D3 and D4 droughts and fewer D1 and D2 droughts. This pattern is reversed during the cool season (November-February), when there are more D1 and D2 droughts and fewer D3 and D4 droughts. Therefore, monthly objective drought thresholds were developed for each location by fitting the SPI data separately for each month. Monthly objective drought thresholds do not remove the seasonal variations shown in Fig. 5 but provide a unique consideration in comparison to fixed and objective thresholds.

Figure 6 shows the variation in the monthly objective drought thresholds for D4 events based on all SPI time scales. While this figure only displays the monthly objective D4 thresholds, similar patterns are observed for the other drought severity categories (D1, D2, and D3). The results indicate that there are only seasonal variations in the magnitude of D4 thresholds when using the 1-month SPI. This seasonal trend does indicate that the D4 thresholds tend to be more extreme during the warm season (July-October) and less extreme during the cool season. This may occur due to rapid drying that can occur during the warm season (Ryu and Hayhoe 2017). In addition, the variation across the study region is much greater in the winter and much more homogeneous during the summer. This seasonal variation in objective drought thresholds appears to be driven by seasonal precipitation patterns when using the 1-month SPI. The largest mean monthly precipitation gradients in this area occur during the winter and spring seasons, and the range of D4 thresholds is greatest at this time. During May, June, July, and August there are locations within the study region where the monthly objective drought severity thresholds are more extreme than the fixed thresholds. This suggests that the biases in the fixed drought thresholds can vary with both space and time and that there is not a consistent bias (over- or underestimating drought severity) when using fixed drought thresholds. Similar to the observed seasonal frequencies with the SPI, the SPI values of the D4 threshold are less variant for longer time scales of the SPI. Longer time scales are less likely to display clear seasonal patterns because the calculation of the index accumulates monthly SPI values as the length of the time scale increases.

\section{c. Objective drought thresholds: An application}

The following section will examine the impact of objective drought thresholds on the drought climatology when variance is largest with the 1-month SPI. The frequency of occurrence for each drought severity category was determined using the newly developed objective drought thresholds (Fig. 7). The impact of applying objective thresholds with the 1-month SPI is shown for both D0 and D4 conditions. For D0 conditions, objective thresholds reduced the number of outlying higher-severity frequencies located in west Texas. Monthly objective drought thresholds further reduced the higher frequencies of D0 conditions so that variations in D0 frequencies appear to have no clear spatial 
1-Month SPI

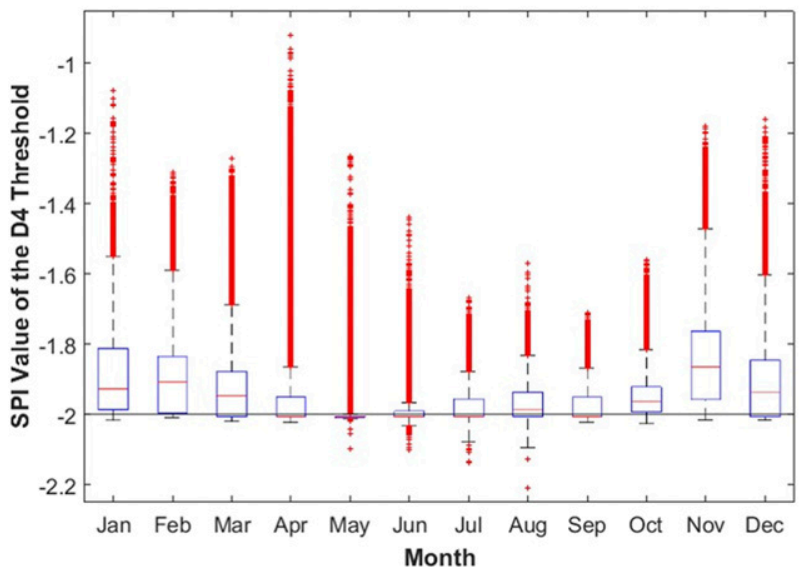

6-Month SPI

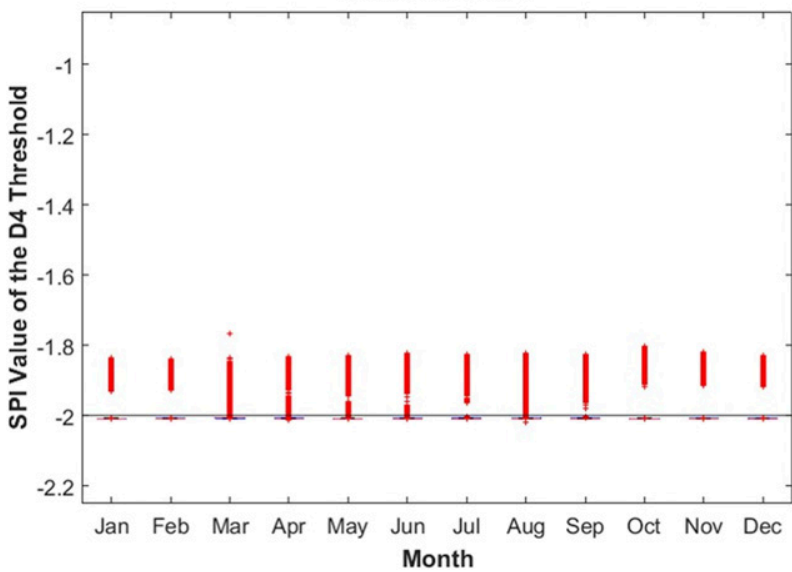

3-Month SPI

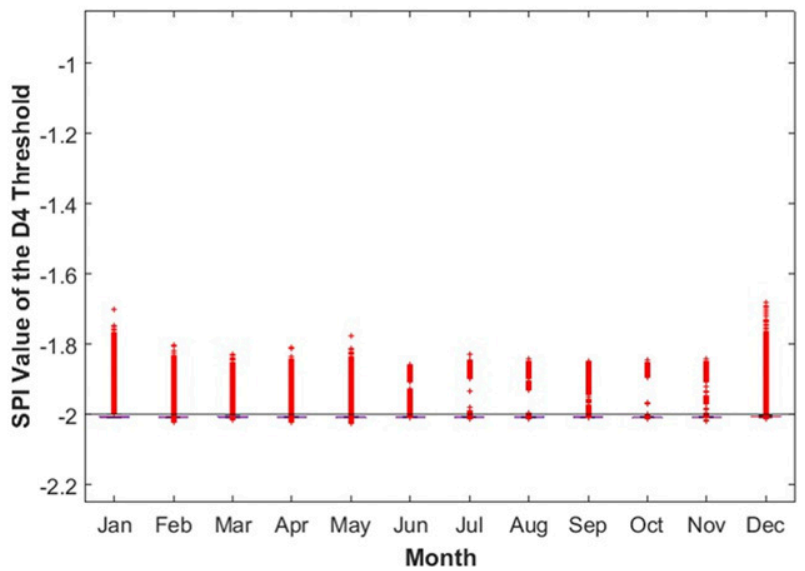

12-Month SPI

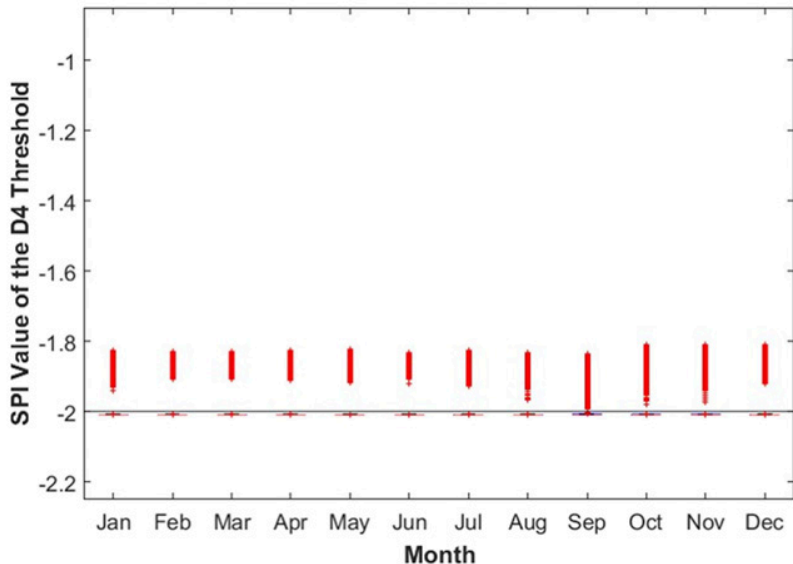

FIG. 6. Distributions of monthly objective drought thresholds for the 1-, 3-, 6-, and 12-month SPI across the study region for D4 events. The solid horizontal black line represents the fixed USDM threshold $(-2)$. The top of each box represents the 75th percentile of the distribution, and the bottom represents the 25 th percentile. The solid horizontal red line in the box displays the median of the distribution. Whiskers extend to \pm 2.7 standard deviations from the mean, and all other values are considered to be outliers and are plotted as red dots.

pattern. When considering D4 conditions, monthly objective drought thresholds now match the expected drought frequency in $19.5 \%$ of the study region and the objective drought thresholds match the expected drought frequency $(0.9 \leq$ proportion $\leq 1.1)$ in $30.4 \%$ of the study region. While both sets of objective thresholds improve upon the fixed thresholds $(17.5 \%)$, it is clear that objective thresholds perform better than monthly objective thresholds. In particular, there is improvement in the relatively dry western part of the study region. There are still locations where the observed drought frequencies do not match the expected drought frequencies. These are locations where the precipitation distribution does not match either the lognormal or normal distributions very well. In the future, the method for establishing objective drought thresholds could be further improved to test other distributions that may better fit the hydroclimatic conditions (drought climatology) in regions with heterogeneous severity frequencies where it is more difficult to adjust thresholds to the historical distributions of the SPI.

The aforementioned analysis has only examined the overall changes in the frequency of occurrence for each drought severity category after applying objective drought thresholds. Given that the motivation for developing more appropriate drought thresholds is to facilitate better management of drought risk and to enhance drought mitigation and response activities, it is also useful to demonstrate the utility of objective drought thresholds by examining a single drought event. Figure 8 shows the evolution of the 2011 drought in the study region using the 1-month SPI. Drought begin to impact the south-central United States in late 2010 with dry conditions persisting into 2012. In Texas, 2011 was recorded as the state's driest year on record (NielsenGammon 2012). The 2011 drought in Texas resulted in 


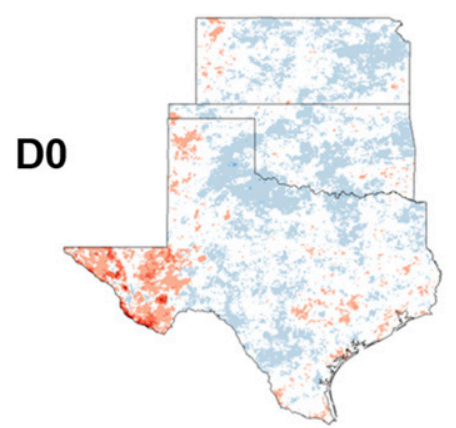

Fixed

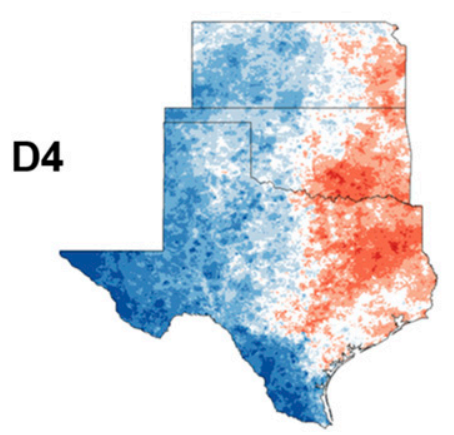

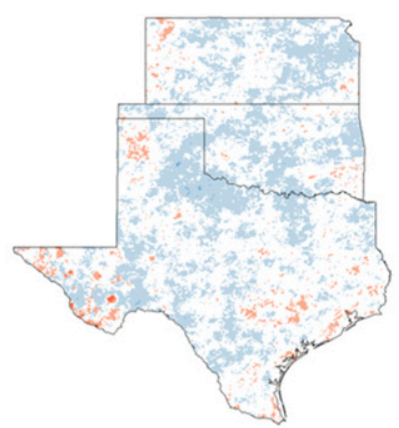

Objective

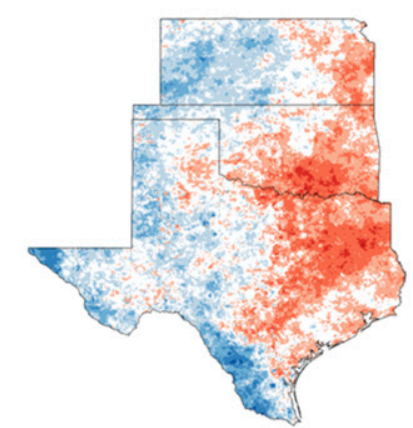

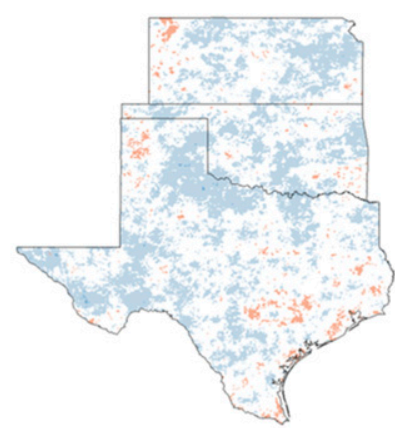

Monthly Objective

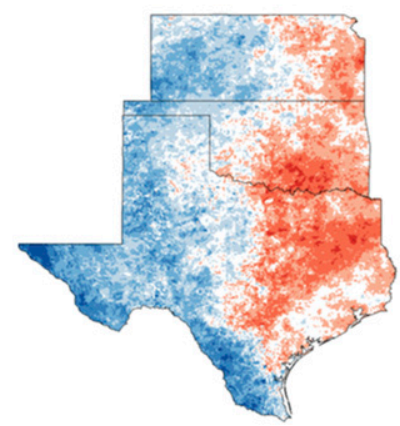

Proportional

Change in

Severity

Frequencies

(1-Month SPI)

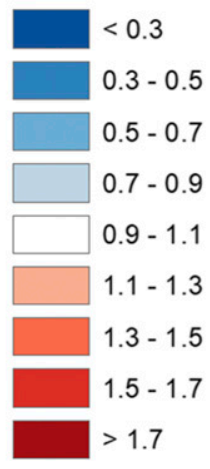

FIG. 7. Comparison of the proportional difference in (top) D0 and (bottom) D4 frequencies for 1-month SPI values from 1900 to 2015 using (left) fixed, (center) objective, and (right) monthly objective severity thresholds.

7.62 billion dollars in losses from the agricultural economy (Combs 2014). The proportion of the study area in drought is shown for the fixed, objective and monthly objective methods. Overall, there are not substantial differences between these three methods in terms of the total area that was in drought, especially for D1 to D3 conditions. However, the largest differences between the three methods occur when examining D4 conditions. Both the objective and monthly objective methods indicate that a greater proportion of the study region experienced D4 conditions than is indicated by the fixed drought thresholds. This is noteworthy because the tendency for the SPI to underrepresent drought severity is most likely to occur in conjunction with the most extreme drought impacts (Fig. 4). Utilizing objective drought thresholds with the 1-month SPI would have increased the drought severity from D3 to D4 across an area of $74448 \mathrm{~km}^{2}$ during June-August in 2011 (see Table B1 in appendix B). The locations where differences in drought severity were observed occurred across the entire study area, but they were most concentrated in the western portion of the region (results not shown). The largest differences in drought severity classifications using different sets of thresholds are observed with the 1-month SPI. While the 1-month SPI would not regularly be used to denote severities for medium- and long-term droughts, misclassifications with the 1-month SPI may have obscured rapid drought development trends that would occur with precipitation deficits and high potential evapotranspiration. When using longer SPI time scales to monitor the 2011 drought, the severity classification was raised to D4 across an area of $2736 \mathrm{~km}^{2}$ for the 3-month SPI, $5280 \mathrm{~km}^{2}$ for the 6-month SPI, and $17840 \mathrm{~km}^{2}$ for the 12-month SPI (see Table B1 in appendix B).

When considering all drought severities during the same subset of the 2011 drought, the net result is that drought was misclassified in $8.3 \%$ of the study area when using fixed drought thresholds based on the 1-month SPI. That is, $8.3 \%$ of grid cells experienced a difference in drought severity classification of at least one USDM category when using objective instead of fixed thresholds. However, when using the 3-, 6-, and 12-month SPI, drought severity was only misclassified in $0.2 \%, 0.5 \%$, and $1.3 \%$ of the study area, respectively (see Table B2 in appendix B). Therefore, the SPI at longer time scales is less sensitive to how the drought thresholds are defined. Nonetheless, the analysis of the 2011 drought event illustrates that if one was relying solely on the SPI to identify drought severity, the severity of drought in some regions would have been overestimated, while in other areas it would have been underestimated. This is one of the many reasons why the USDM uses a convergence-of-evidence approach 

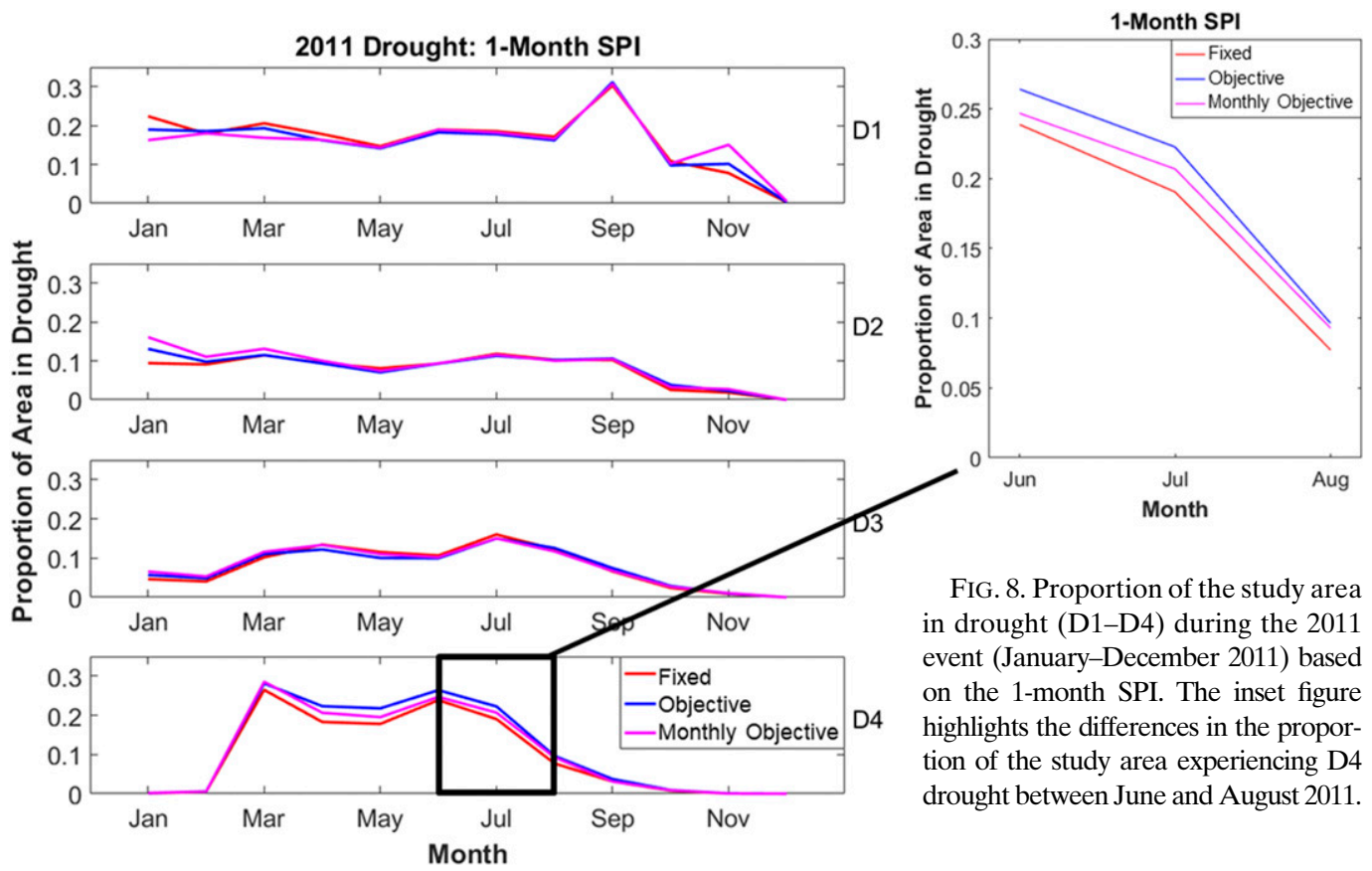

FIG. 8. Proportion of the study area in drought (D1-D4) during the 2011 event (January-December 2011) based on the 1-month SPI. The inset figure highlights the differences in the proportion of the study area experiencing D4 drought between June and August 2011.

to determine drought severity and no single drought index should be used to determine drought severity. The 2011 drought was an exceptional event, but similar misclassification of drought severity is evident in other droughts that we have analyzed. Adopting objective drought thresholds will help to minimize these misclassification issues.

\section{Discussion and limitations}

Relatively few studies have attempted to develop a process that establishes objective thresholds for drought monitoring. This paper builds on previous work to illustrate potential biases that result from classifying SPI severities using fixed drought thresholds. Biases vary in both space and time and there is not a consistent bias (over or underestimating drought severity) when using fixed drought thresholds. However, the biases reveal that drought classification can be sensitive to the use of fixed severity threshold definitions across varying climates. For example, objective drought thresholds using the 1-month SPI tend to be less severe than fixed drought thresholds in semiarid and arid regions, and these results agree with Goodrich and Ellis (2006) and Quiring (2009b). Since this paper uses a higher-resolution dataset, the results identify the spatial patterns more clearly than previous studies (Goodrich and Ellis 2006; Quiring 2009b). At longer SPI time scales, disproportionate severities are still present, but the lack of a clear spatial pattern prevents us from attributing the variance to precipitation characteristics. Longer SPI time scales decrease the probability of no precipitation occurring during the defined time period. Thus, differences among distributions of SPI values are more likely attributed to natural variability than aridity.

Furthermore, because there is significant seasonal variability in precipitation patterns, this paper is the first to develop monthly objective drought thresholds. Using the 1-month SPI, the largest differences in drought thresholds occur during the cool (November-January) and warm (April-September) seasons. Severity thresholds were very similar during the months of March and October. There is an inverse relationship between higher (D3 and D4) and lower (D0, D1, and D2) drought severities. With the 1-month SPI, there are more (less) extreme events during the warm (cool) season. Specifically, the variability in the magnitude of the D4 thresholds is lowest from July to October (Fig. 6). This likely coincides with an increase in precipitation across arid regions in response to the North American monsoon. The gradient in precipitation between El Paso and Tyler is $13.0 \mathrm{~mm}$ in August and $108.7 \mathrm{~mm}$ in May. Since precipitation seasonality is a common feature of many climate regions within North America and around the world, thresholds that are standardized for each month may best represent the recurrence intervals for any given month. However, our results do not suggest that monthly objective thresholds alleviate variability in severity frequencies when compared with thresholds 

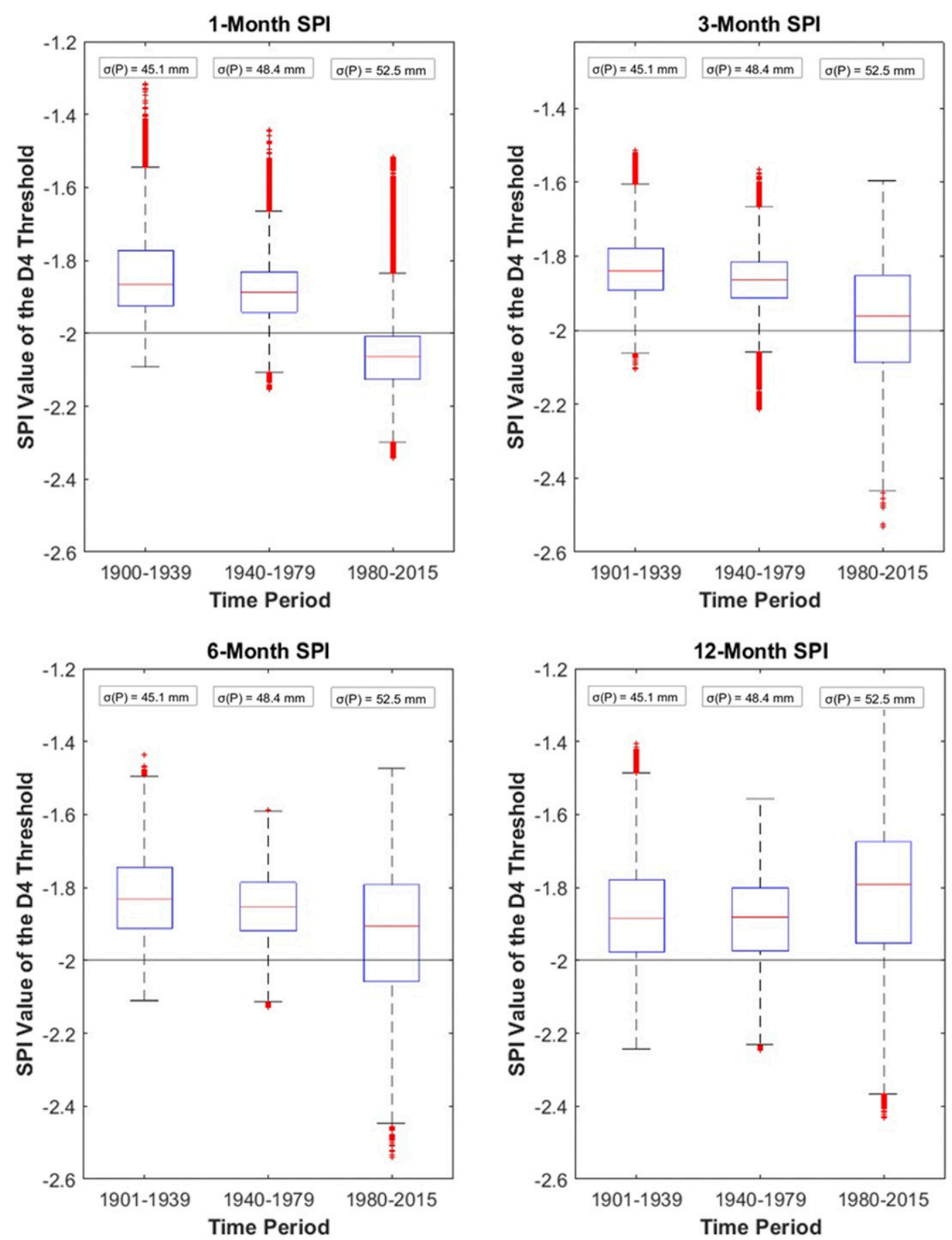

FIG. 9. Distributions of objective drought thresholds for the 1-, 3-, 6-, and 12-month SPI time scales across the study region for D4 events. Each time period represents a unique set of years that was used to calculate objective drought thresholds. The solid horizontal black line represents the fixed USDM threshold ( -2$)$. The standard deviation of precipitation averaged across the study area is also shown for each time period. The top of each box represents the 75 th percentile of the distribution, and the bottom represents the 25 th percentile. The solid red line displays the median of the distribution. Whiskers extend to \pm 2.7 standard deviations from the mean, and all other values are considered to be outliers and are plotted as red dots. 


\section{3-Month SPI}
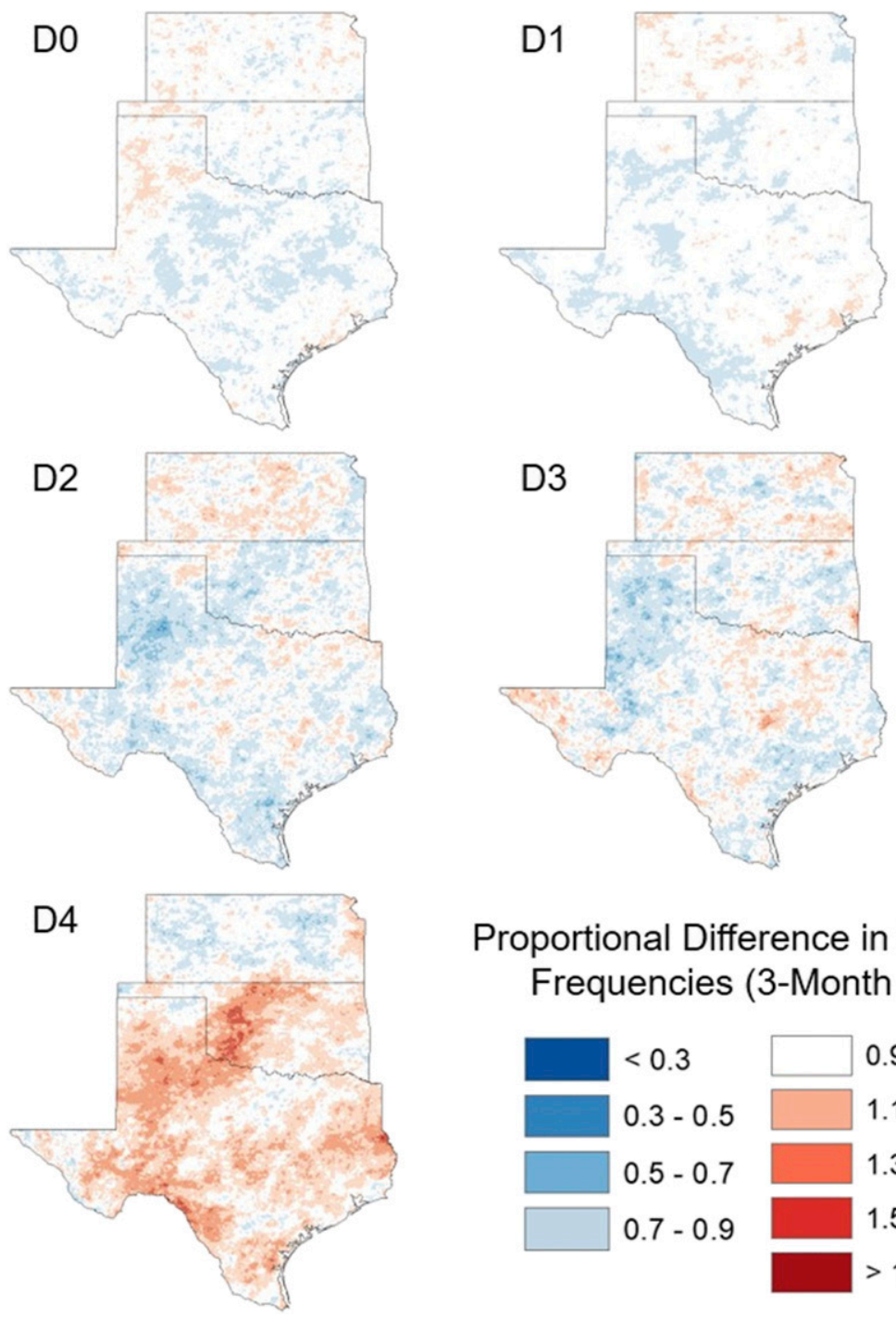

\section{Proportional Difference in Severity Frequencies (3-Month SPI)}

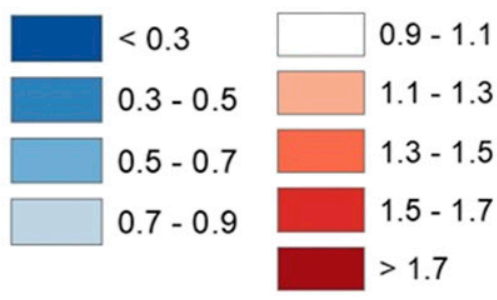

FIG. A1. Proportional difference in frequency associated with each USDM severity category (Table 1) between 1901 and 2015 based on the 3-month SPI. The proportional difference represents the number of months in which a given severity occurred divided by the theoretical (or expected) frequency shown in Table 1. Areas in blue indicate that the number of droughts of a given severity (D0-D4) occur less frequently than expected. Areas in red indicate that droughts of a given severity (D0-D4) occur more frequently than expected. If the observed frequency matches the theoretical frequency established by USDM, then most values should be near 1 (white).

that do not vary by month. However, results (Fig. 5) do suggest that it is important to consider that the probability of exceedance for a given threshold can vary by month. Note also that monthly objective drought thresholds are most important when looking at relatively short time scales (e.g., 1-3-month SPI) when months with no precipitation have the largest impact on SPI distributions. It is less important to develop monthly objective drought thresholds when examining longer time scales ( $>6$ months). Monthly objective drought thresholds may have the most utility when monitoring flash drought conditions in diverse climates.

The proposed method did not consider how drought thresholds may change with time. Figure 9 displays evidence that some locations have seen drought thresholds become more extreme over the last 35 years as the variability of observed precipitation also increases. However, as the SPI time scale increases, the tendency 


\section{6-Month SPI}
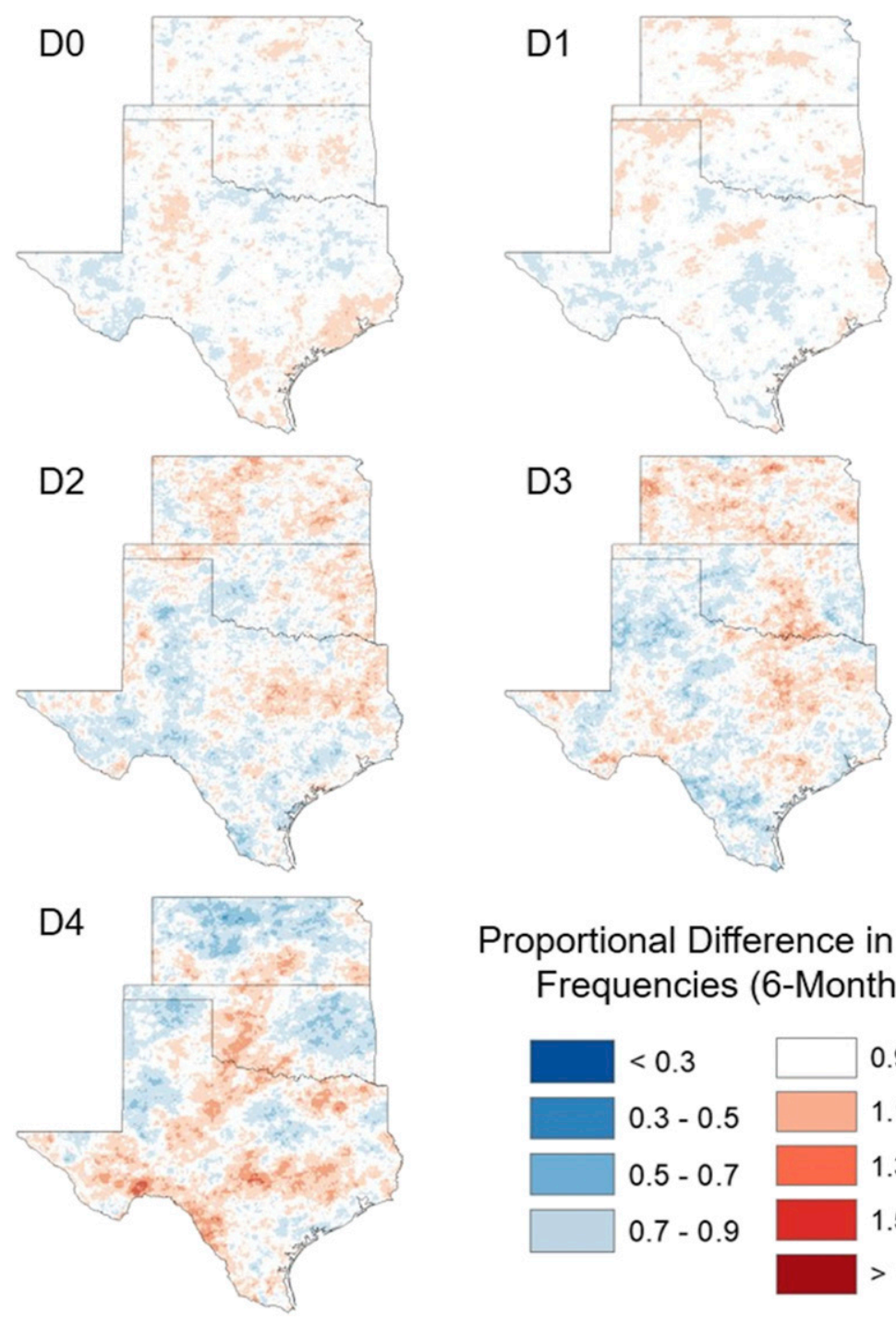

\section{Proportional Difference in Severity Frequencies (6-Month SPI)}

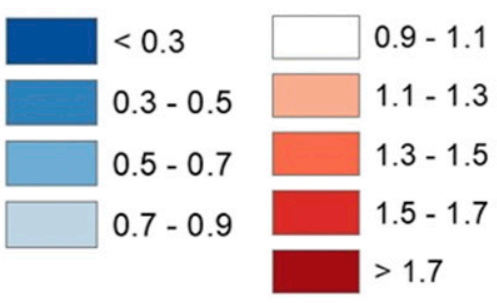

FIG. A2. As in Fig. A1, but based on the 6-month SPI.

for drought thresholds to become more extreme decreases. This demonstrates that thresholds are more sensitive to the increasing intra-annual precipitation variability at short SPI time scales. While this is an important consideration in a changing climate, this study only examined geographically dependent drought thresholds to examine problems with using fixed drought thresholds across diverse climates. The increasing variability of the SPI may be attributed to anthropogenic climate change or an increase in the number of stations included in the PRISM dataset over time. It is possible that problems may arise when calculating severity thresholds using a time series that is nonstationary. Methods that rely on stationarity of the climate record may no longer be suitable because the impacts of climate change will also result in changes to drought frequencies and severities. This is likely to occur in the future as projections of climate change suggest an increase the variability of the SPI across the southern Great Plains (Swain and Hayhoe 2015). Objective drought thresholds provide an opportunity to better reflect changes in drought severities according to changes in climatic characteristics. Potential trends in the magnitude of precipitation may also have an effect on the calculation of the SPI, and it is important to consider how the period of record chosen to calculate the thresholds may impact the SPI. Studies that employ fixed definitions of drought may inherently mischaracterize 


\section{2-Month SPI}
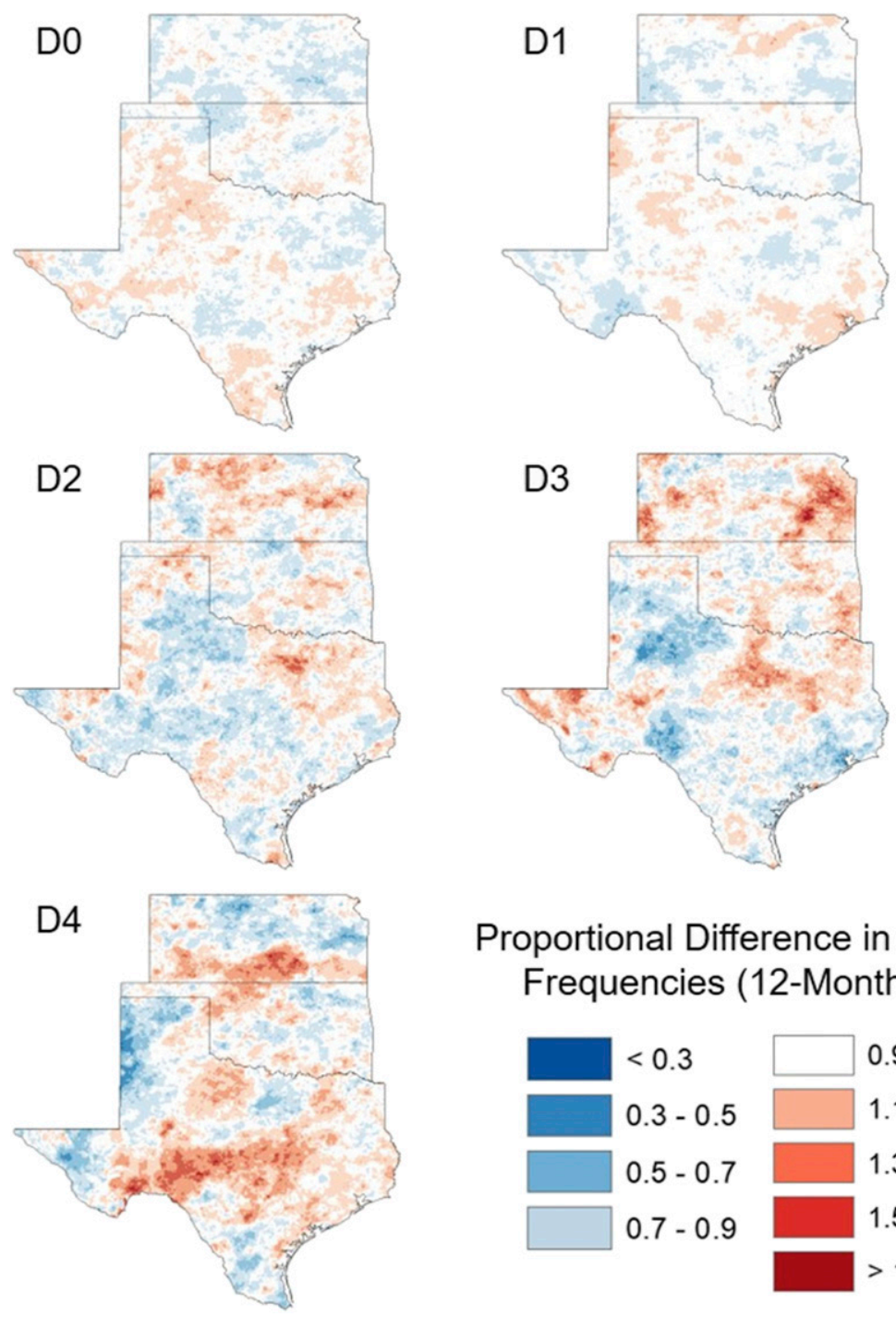

\section{Proportional Difference in Severity Frequencies (12-Month SPI)}

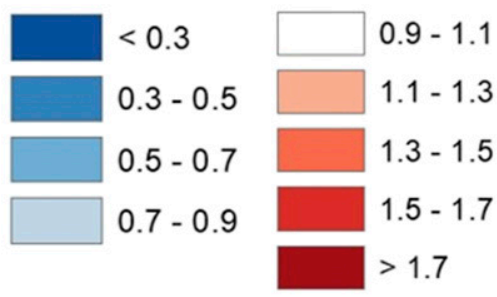

FIG. A3. As in Fig. A1, but based on the 12-month SPI.

projections of drought by not allowing thresholds to reflect the empirical recurrence intervals that represent each occurrence of drought.

A final limitation of this study is that, after the SPI values were calculated, we compared how well the normal and lognormal distributions fit the SPI at each location in the study region. Other distributions could have been considered. Quiring (2009b) also evaluated gamma and exponential distributions. However, given that these distributions were fit separately at each of the 60634 grid cells, we chose to focus on the two distributions that were likely to provide the best fit. We acknowledge that at some locations in the study region, there may be other distributions that fit the SPI better and therefore are more appropriate for calculating objective drought thresholds at those locations. The methods that are used in this study provide a framework that could be expanded to objectively consider the performance of other distributions and drought indices. Future research could explore additional CDFs that could be used to fit distributions of SPI and further reduce the variance of the index.

\section{Conclusions}

There are substantial spatial and temporal variations in objectively defined drought severity thresholds across 
TABLE B1. Case study displaying the occurrence of D4 conditions in the study area before and after applying both objective and monthly objective drought thresholds during a 3-month portion of the 2011 drought.

\begin{tabular}{|c|c|c|c|c|c|c|}
\hline Month & $\begin{array}{l}\text { Objective D4 diff } \\
\text { (no. of grid cells) }\end{array}$ & $\begin{array}{l}\text { Monthly objective D4 diff } \\
\text { (no. of grid cells) }\end{array}$ & $\begin{array}{c}\text { Objective } \\
\text { D4 diff (\%) }\end{array}$ & $\begin{array}{l}\text { Monthly objective } \\
\text { D4 diff (\%) }\end{array}$ & $\begin{array}{l}\text { Objective D4 } \\
\text { diff }\left(\mathrm{km}^{2}\right)\end{array}$ & $\begin{array}{l}\text { Monthly objective } \\
\text { D4 diff }\left(\mathrm{km}^{2}\right)\end{array}$ \\
\hline \multicolumn{7}{|c|}{ 1-month SPI time scale } \\
\hline Jun & 1540 & 492 & 2.5 & 0.8 & 24640 & 7872 \\
\hline Jul & 1954 & 998 & 3.2 & 1.6 & 31264 & 15968 \\
\hline Aug & 1159 & 947 & 1.9 & 1.6 & 18544 & 15152 \\
\hline Total & 4653 & 2437 & 2.6 & 1.3 & 74448 & 38992 \\
\hline \multicolumn{7}{|c|}{ 3-month SPI time scale } \\
\hline Jun & 46 & -114 & 0.1 & 0.2 & 736 & 1824 \\
\hline Jul & 58 & -150 & 0.1 & 0.2 & 928 & 2400 \\
\hline Aug & 67 & -171 & 0.1 & 0.3 & 1072 & 2736 \\
\hline Total & 171 & -435 & 0.1 & 0.2 & 2736 & 6960 \\
\hline \multicolumn{7}{|c|}{ 6-month SPI time scale } \\
\hline Jun & 131 & -15 & 0.2 & $<0.1$ & 2096 & 240 \\
\hline Jul & 121 & 2 & 0.2 & $<0.1$ & 1936 & 32 \\
\hline Aug & 78 & -61 & 0.1 & 0.1 & 1248 & 976 \\
\hline Total & 330 & -74 & 0.2 & $<0.1$ & 5280 & 1184 \\
\hline \multicolumn{7}{|c|}{ 12-month SPI time scale } \\
\hline Jun & 215 & 62 & 0.4 & 0.1 & 3440 & 992 \\
\hline Jul & 566 & 326 & 0.9 & 0.5 & 9056 & 5216 \\
\hline Aug & 334 & 152 & 0.6 & 0.3 & 5344 & 2432 \\
\hline Total & 1115 & 540 & 0.6 & 0.3 & 17840 & 8640 \\
\hline
\end{tabular}

the south-central United States. This is due to the significant regional and seasonal variations in precipitation. Locations (and seasons) that experience months with little or no precipitation have a significant influence on the calculation of the SPI at short time scales. In semiarid and arid regions, the more extreme drought categories are systematically underrepresented when using fixed drought thresholds. Thus, when comparing climatically diverse regions such as the south-central United States, the use of fixed drought thresholds is not appropriate, especially for short-term SPI time scales. At longer SPI time scales, variant severity frequencies illustrate that objective drought thresholds can still have utility where SPI data do not follow a normal distribution.

In this study, both objective and monthly objective drought thresholds were developed for the study area to quantify the variability in drought severity thresholds across the region and to provide a more appropriate means of determining drought severity in each location. The results show that geographically dependent severity thresholds impact the characteristics of drought according to the SPI. The objectively defined drought thresholds tended to reduce the spatial biases in the observed drought severity. When using the 1-month SPI, there are also seasonal biases in the drought severity thresholds and therefore a similar method was used to develop monthly objective thresholds. The importance of objective drought thresholds was demonstrated by quantifying the differences in the highest drought severities during the 2011 drought. Objective drought thresholds suggest an area of $74448 \mathrm{~km}^{2}$ had a difference in drought severity of one USDM category when comparing the fixed drought thresholds with the objective drought thresholds for the 1-month SPI D4 threshold. Considering the average county size for the study area according to the 2010 census $\left(2329 \mathrm{~km}^{2}\right)$, approximately 32 counties would have underrepresented the D4 classification. Using the 3-month SPI, 1 county underrepresented D4 conditions, 2 counties underrepresented D4 conditions using the 6-month SPI, and 8 counties underrepresented D4 conditions using the 12-month SPI (see Table B1 in appendix B). The 1-month SPI may not be the best indicator of agricultural or hydrological drought events, but this index is a key component used in the convergence-of-evidence approach employed by the USDM. National maps of the 1-month SPI are frequently shown using fixed thresholds. Thus, it is possible that biases in drought depiction may propagate into consensus classifications by USDM or objective blends of drought indices.

This paper has direct implications for real-time drought monitoring activities, such as the USDM. It demonstrates the biases resulting from using the SPI in conjunction with fixed thresholds to monitor shortterm precipitation deficits. The methods used in this 
TABLE B2. Case study displaying the frequencies of drought severity reclassification for all (D0-D4) USDM severity categories before and after applying both objective and monthly objective drought thresholds during a 3-month portion of the 2011 drought.

\begin{tabular}{|c|c|c|c|c|c|c|}
\hline Month & $\begin{array}{l}\text { Objective } \\
\text { reclassification } \\
\text { frequency (no. of } \\
\text { grid cells) }\end{array}$ & $\begin{array}{l}\text { Monthly objective } \\
\text { reclassification } \\
\text { frequency (no. of } \\
\text { grid cells) }\end{array}$ & $\begin{array}{c}\text { Objective } \\
\text { reclassification } \\
\text { frequency }(\%)\end{array}$ & $\begin{array}{l}\text { Monthly objective } \\
\text { reclassification } \\
\text { frequency }(\%)\end{array}$ & $\begin{array}{c}\text { Objective } \\
\text { reclassification } \\
\text { frequency }\left(\mathrm{km}^{2}\right)\end{array}$ & $\begin{array}{l}\text { Monthly objective } \\
\text { reclassification } \\
\text { frequency }\left(\mathrm{km}^{2}\right)\end{array}$ \\
\hline \multicolumn{7}{|c|}{ 1-month SPI time scale } \\
\hline Jun & 4831 & 1921 & 8.0 & 3.2 & 77296 & 30736 \\
\hline Jul & 5284 & 2400 & 8.7 & 4.0 & 84544 & 38400 \\
\hline Aug & 5058 & 2932 & 8.3 & 4.8 & 80928 & 46912 \\
\hline Total & 15173 & 7253 & 8.3 & 4.0 & 242768 & 116048 \\
\hline \multicolumn{7}{|c|}{ 3-month SPI time scale } \\
\hline Jun & 106 & 411 & 0.2 & 0.7 & 1696 & 6576 \\
\hline Jul & 147 & 528 & 0.2 & 0.9 & 2352 & 8448 \\
\hline Aug & 162 & 486 & 0.3 & 0.8 & 2592 & 7776 \\
\hline Total & 415 & 1425 & 0.2 & 0.8 & 6640 & 22800 \\
\hline \multicolumn{7}{|c|}{ 6-month SPI time scale } \\
\hline Jun & 391 & 798 & 0.6 & 1.3 & 6256 & 12768 \\
\hline Jul & 250 & 495 & 0.4 & 0.8 & 4000 & 7920 \\
\hline Aug & 193 & 502 & 0.3 & 0.8 & 3088 & 8032 \\
\hline Total & 834 & 1795 & 0.5 & 1.0 & 13344 & 28720 \\
\hline \multicolumn{7}{|c|}{ 12-month SPI time scale } \\
\hline Jun & 832 & 1342 & 1.4 & 2.2 & 13312 & 21472 \\
\hline Jul & 893 & 1350 & 1.5 & 2.2 & 14288 & 21600 \\
\hline Aug & 607 & 932 & 1.0 & 1.5 & 9712 & 14912 \\
\hline Total & 2332 & 3624 & 1.3 & 2.0 & 37312 & 57984 \\
\hline
\end{tabular}

paper can be applied to any drought index and in any part of the world to determine objective, operational drought severity thresholds. Decision-makers should use the most recent historical data to calculate objective drought thresholds in real time because this research shows that severity thresholds may change with time, especially at shorter SPI time scales. These objectively defined drought thresholds help to overcome the spatial and temporal biases in drought thresholds. A critical evaluation of bias in drought thresholds is essential given that these drought thresholds are often used in the convergence-of-evidence approach for drought mitigation and drought response. For example, some municipalities use drought thresholds to trigger water conservation measures. The USDA's Farm Service Agency uses drought thresholds to determine where and when to provide relief through the Livestock Forage Disaster Program (LFP), Livestock Indemnity Program (LIP), Emergency Assistance for Livestock, Honeybees, and Farm-Raised Fish Program (ELAP), and Tree Assistance Program (TAP). Therefore, it is important to use the best possible information to accurately determine the severity of drought.

Drought indices are an important tool for managing climate risk. However, as demonstrated in this paper, drought mitigation activities or disaster declarations should not solely rely upon fixed thresholds using the
SPI because the probability of exceeding a drought threshold may vary in space and time. Therefore, it is important to objectively establish drought thresholds as a complementary tool for operational drought monitoring. This data-driven method objectively provides location-specific drought thresholds that better represent the historical recurrence intervals associated with the USDM definitions. When monitoring drought with short time scales of the SPI, we recommend using objective drought thresholds, especially in arid regions. These approaches are also particularly important given the impact that anthropogenic climate change will have on precipitation patterns. Objective drought thresholds can be used to both track the impact of climate change on drought frequency and severity and to establish drought thresholds that are based on the new normal.

\section{APPENDIX A}

\section{Drought Severity Frequencies at Longer SPI Time Scales}

Figures A1-A3 show the proportional difference in frequency associated with each USDM severity category on the basis of the 3-, 6-, and 12-month SPI, respectively. 


\section{APPENDIX B}

\section{Drought Case Study}

Tables B1 and B2 display potential changes in drought severity classification using objective and monthly objective thresholds during June, July, and August of the 2011 drought. Table B1 shows the occurrence of D4 conditions in the study area before and after applying both objective and monthly objective drought thresholds. Table B2 shows the frequencies of drought severity reclassification for all (D0-D4) USDM severity categories before and after applying both objective and monthly objective drought thresholds.

\section{REFERENCES}

Basara, J. B., J. N. Maybourn, C. M. Peirano, J. E. Tate, P. J. Brown, J. D. Hoey, and B. R. Smith, 2013: Drought and associated impacts in the Great Plains of the United States-A review. Int. J. Geosci., 04, 72-81, https://doi.org/10.4236/ijg.2013.46A2009.

Christian, J. I., J. B. Basara, J. A. Otkin, E. D. Hunt, R. A. Wakefield, P. X. Flanagan, and X. Xiao, 2019: A methodology for flash drought identification: Application of flash drought frequency across the United States. J. Hydrometeor., 20, 833846, https://doi.org/10.1175/JHM-D-18-0198.1.

Combs, S., 2014: Texas water report: Going deeper for the solution. Texas Comptroller of Public Accounts Rep., 24 pp., https://cdn.ymaws.com/www.taccbo.org/resource/resmgr/2014 Galveston_Presentations/3-1_TX_Water_Report_96-1746.pdf.

Daly, C., R. P. Neilson, and D. L. Phillips, 1994: A statisticaltopographic model for mapping climatological precipitation over mountainous terrain. J. Appl. Meteor., 33, 140-158, https://doi.org/ 10.1175/1520-0450(1994)033<0140:ASTMFM > 2.0.CO;2.

— , G. H. Taylor, W. P. Gibson, T. W. Parzybok, G. L. Johnson, and P. A. Pasteris, 2000: High-quality spatial climate data sets for the United States and beyond. Trans. ASAE, 43, 19571962, https://doi.org/10.13031/2013.3101.

, M. Halbleib, J. I. Smith, W. P. Gibson, M. K. Doggett, G. H. Taylor, J. Curtis, and P. P. Pasteris, 2008: Physiographically sensitive mapping of climatological temperature and precipitation across the conterminous United States. Int. J. Climatol. 28, 2031-2064, https://doi.org/10.1002/joc.1688.

Goodrich, G. B., and A. W. Ellis, 2006: Climatological drought in Arizona: An analysis of indicators for guiding the governor's drought task force. Prof. Geogr., 58, 460-469, https://doi.org/ 10.1111/j.1467-9272.2006.00582.x

Guttman, N. B., 1999: Accepting the standardized precipitation index: A calculation algorithm. J. Amer. Water Resour. Assoc., 35, 311-322, https://doi.org/10.1111/j.1752-1688.1999.tb03592.x.

Hayes, M., M. Svoboda, N. Wall, and M. Widhalm, 2011: The Lincoln declaration on drought indices: Universal meteorological drought index recommended. Bull. Amer. Meteor. Soc., 92, 485-488, https://doi.org/10.1175/2010BAMS3103.1.

Heim, R. R., 2002: A review of twentieth-century drought indices used in the United States. Bull. Amer. Meteor. Soc., 83, 11491166, https://doi.org/10.1175/1520-0477-83.8.1149.

Hodges, D., and Z. Pu, 2019: Characteristics and variations of lowlevel jets and environmental factors associated with summer precipitation extremes over the Great Plains. J. Climate, 32, 5123-5144, https://doi.org/10.1175/JCLI-D-18-0553.1.
Ji, L., and A. J. Peters, 2003: Assessing vegetation response to drought in the northern Great Plains using vegetation and drought indices. Remote Sens. Environ., 87, 85-98, https:// doi.org/10.1016/S0034-4257(03)00174-3.

Kam, J., J. Sheffield, X. Yuan, and E. F. Wood, 2013: The influence of Atlantic tropical cyclones on drought over the eastern United States (1980-2007). J. Climate, 26, 3067-3086, https:// doi.org/10.1175/JCLI-D-12-00244.1.

McKee, T. B., N. J. Doesken, and J. Kleist, 1993: The relationship of drought frequency and duration to time scales. Proc. Eighth Conf. on Applied Climatology, Anaheim, CA, Amer. Meteor. Soc., 179-183.

Mo, K. C., 2011: Drought onset and recovery over the United States. J. Geophys. Res., 116, D20106, https://doi.org/10.1029/ 2011JD016168.

_ - and J. E. Schemm, 2008: Droughts and persistent wet spells over the United States and Mexico. J. Climate, 21, 980-994, https://doi.org/10.1175/2007JCLI1616.1.

$\longrightarrow,-$, and S.-H. Yoo, 2009: Influence of ENSO and the Atlantic multidecadal oscillation on drought over the United States. J. Climate, 22, 5962-5982, https://doi.org/10.1175/2009JCLI2966.1.

Nielsen-Gammon, J. W., 2012: The 2011 Texas drought. Tex. Water $J ., 3,59-95$.

Otkin, J. A., M. Svoboda, E. D. Hunt, T. W. Ford, M. C. Anderson, C. Hain, and J. B. Basara, 2018: Flash droughts: A review and assessment of the challenges imposed by rapid-onset droughts in the United States. Bull. Amer. Meteor. Soc., 99, 911-919, https://doi.org/10.1175/BAMS-D-17-0149.1.

Peel, M. C., B. L. Finlayson, and T. A. McMahon, 2007: Updated world map of the Köppen-Geiger climate classification. Hydrol. Earth Syst. Sci., 11, 1633-1644, https://doi.org/10.5194/hess-111633-2007.

Pu, B., R. Fu, R. E. Dickinson, and D. N. Fernando, 2016: Why do summer droughts in the southern Great Plains occur in some La Niña years but not others? J. Geophys. Res. Atmos., 121, 1120-1137, https://doi.org/10.1002/2015JD023508.

Quiring, S. M., 2009a: Monitoring drought: An evaluation of meteorological drought indices. Geogr. Compass, 3, 64-88, https://doi.org/10.1111/j.1749-8198.2008.00207.x.

- 2009b: Developing objective operational definitions for monitoring drought. J. Appl. Meteor. Climatol., 48, 1217-1229, https://doi.org/10.1175/2009JAMC2088.1.

Razali, N. M., and Y. B. Wah, 2011: Power comparisons of ShapiroWilk, Kolmogorov-Smirnov, Lilliefors and Anderson-Darling tests. J. Stat. Modell. Anal., 2, 21-33.

Ryu, J.-H., and K. Hayhoe, 2017: Observed and CMIP5 modeled influence of large-scale circulation on summer precipitation and drought in the south-central United States. Climate Dyn., 49 4293-4310, https://doi.org/10.1007/s00382-017-3534-z.

Song, F., Z. Feng, L. R. Leung, R. A. Houze Jr., J. Wang, J. Hardin, and C. R. Homeyer, 2019: Contrasting spring and summer large-scale environments associated with mesoscale convective systems over the U.S. Great Plains. J. Climate, 32, 6749-6767, https://doi.org/10.1175/JCLI-D-18-0839.1.

Soulé, P. T., 1992: Spatial patterns of drought frequency and duration in the contiguous USA based on multiple drought event definitions. Int. J. Climatol., 12, 11-24, https://doi.org/10.1002/joc.3370120103.

Steiner, J. L., D. D. Briske, D. P. Brown, and C. M. Rottler, 2018: Vulnerability of southern plains agriculture to climate change. Climatic Change, 146, 201-218, https://doi.org/10.1007/s10584017-1965-5.

Svoboda, M. D., 2016: Essays on decision support for drought mitigation planning: A tale of three tools. Ph.D. dissertation, University 
of Nebraska-Lincoln, 128 pp., https://search.proquest.com/ docview/1823404776.

- and Coauthors, 2002: The Drought Monitor. Bull. Amer. Meteor. Soc., 83, 1181-1190, https://doi.org/10.1175/1520-0477-83.8.1181.

Swain, S., and K. Hayhoe, 2015: CMIP5 projected changes in spring and summer drought and wet conditions over North America. Climate Dyn., 44, 2737-2750, https://doi.org/10.1007/s00382-014-2255-9.

Vicente-Serrano, S. M., and J. I. López-Moreno, 2005: Hydrological response to different time scales of climatological drought: An evaluation of the standardized precipitation index in a mountainous Mediterranean basin. Hydrol. Earth Syst. Sci., 9, 523-533, https://doi.org/10.5194/hess-9523-2005.
— , and Coauthors, 2012: Performance of drought indices for ecological, agricultural, and hydrological applications. Earth Interact., 16, https://doi.org/10.1175/2012EI000434.1.

Wilhite, D., 2000: Drought as a natural hazard: Concepts and definitions. Drought: A Global Assessment, Drought Mitigation Center Faculty Publications, 3-18.

- , and R. S. Pulwarty, 2017: Drought and Water Crises: Integrating Science, Management, and Policy. 2nd ed. CRC Press, $542 \mathrm{pp}$.

Wu, H., M. D. Svoboda, M. J. Hayes, D. A. Wilhite, and F. Wen, 2007: Appropriate application of the standardized precipitation index in arid locations and dry seasons. Int. J. Climatol., 27, 65-79, https://doi.org/10.1002/joc.1371. 